\title{
CONSERVAÇÃO REFRIGERADA DE TANGOR 'MURCOTT' TRATADA TERMICAMENTE
}

\author{
Ana Helena de Felício
}

Dissertação apresentada à Escola Superior de Agricultura "Luiz de Queiroz", Universidade de São Paulo, para obtenção do título de Mestre em Ciências, Área de Concentração: Fisiologia e Bioquímica de Plantas

\author{
PIR A C I C A B A
}

Estado de São Paulo - Brasil

Abril - 2005 


\title{
CONSERVAÇÃO REFRIGERADA DE TANGOR 'MURCOTT' TRATADA TERMICAMENTE
}

\author{
ANA Helena de Felício
}

Engenheiro Agrônomo

Orientador: Prof. Dr. RICARDO ALFREDO KLUGE

Dissertação apresentada à Escola Superior de Agricultura "Luiz de Queiroz", Universidade de São Paulo, para obtenção do título de Mestre em Ciências, Área de Concentração: Fisiologia Bioquímica de Plantas.

PIR A C I C A B A

Estado de São Paulo - Brasil

Abril - 2005 
Dados Internacionais de Catalogação na Publicação (CIP) DIVISÃO DE BIBLIOTECA E DOCUMENTAÇÃO - ESALQ/USP

Felício, Ana Helena

Conservação refrigerada de tangor 'Murcott' tratada termicamente./ Ana Helena de Felício. - Piracicaba, 2005.

57p. : il.

Dissertação (mestrado) - - Escola Superior de Agricultura Luiz de Queiroz, 2005. Bibliografia.

1. Tangerina 2. Fisiologia pós-colheita 3. Conservação de alimentos pelo frio 4. Fungicida 5. Análise de alimento I. Título

CDD 634.31

"Permitida a cópia total ou parcial deste documento, desde que citada a fonte - $\mathrm{O}$ autor" 
Aos meus pais: José Roberto e Ana Silvia, pela confiança, apoio, exemplo e compreensão.

DEDICO.

Ao meu irmão Henrique,

por sua amizade e incentivo.

Aos meus tios João e Adarci,

por terem me dado tanta alegria

com suas presenças.

OFEREÇO. 


\section{AGRADECIMENTOS}

A Deus, por iluminar sempre o meu caminho e pela oportunidade de realizar este trabalho.

Ao Prof. Dr. Ricardo Alfredo Kluge, pela orientação, incentivo, confiança e dedicação.

Ao Conselho do Programa de Pós-Graduação em Fisiologia e Bioquímica de Plantas que me permitiu realizar o Mestrado nessa área tão importante para o país.

Ao Conselho Nacional de Desenvolvimento Científico e Tecnológico (CNPq), pela concessão da bolsa.

Ao Prof. Dr. Angelo Pedro Jacomino, pelas sugestões e apoio durante o curso.

À Profa. Dra. Giuseppina Pace Pereira Lima, por ter me recebido em seu laboratório e ter me incentivado com seu exemplo.

À minha avó Alcy, ao meu avô José (in memorian) e ao tio Pedro que sempre depositaram confiança em mim. 
À querida amiga de Pós-Graduação Maria Carolina Dario Vitti, por seus ensinamentos, ajuda e amizade.

Aos demais estagiários do Laboratório Fisiologia e Bioquímica de Plantas: André (K-minha), Fernando (K-ju) e Vanessa, pela ajuda com os experimentos e agradáveis momentos de convivência.

Aos demais alunos de Pós-Graduação do grupo de Pós-Colheita, Daniela, Fabiana e Juan, pela convivência e troca de informações.

À Ouro do Brasil Comércio de Frutas Ltda., em especial ao Pedro, Álvaro, Edgar e Marcela, pelo fornecimento de frutos para a realização destes trabalhos.

Aos funcionários do Departamento de Produção Vegetal, principalmente ao Eng $^{\circ}$ Agr $^{\circ}$ Marcos José Trevisan, pelo apoio e entrega do Laboratório de PósColheita de Produtos Hortícolas.

À secretária do PPG em Fisiologia e Bioquímica de Plantas, Maria Solizete, por sua competência e disposição para ajudar.

Aos amigos Maria Luiza, Raquel, Ângelo, Karen e Fabiana Bragatto pelo companheirismo, apoio e momentos de diversão.

Aos colegas contemporâneos do PPG em Fisiologia e Bioquímica de Plantas pela agradável convivência.

A todos que de alguma forma contribuíram para a realização deste trabalho. 


\section{SUMÁRIO}

Página

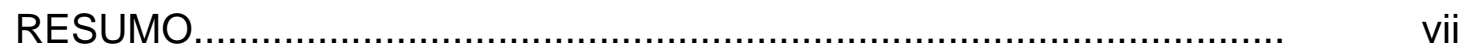



1 INTRODUÇÃO ................................................................. 1

2 REVISÃO DE LITERATURA ….................................................. 3

2.1 Aspectos gerais sobre tangor 'Murcott' ..................................... 3

2.2 Armazenamento refrigerado .............................................. 5

2.3 Danos por frio ............................................................ 5

2.4 Métodos de controle de danos por frio ....................................... 8

2.5 Tratamentos químicos associados ao armazenamento ................... 11

2.6 Aspectos fisiológicos e bioquímicos dos tratamentos térmicos ........ 13

3 MATERIAL E MÉTODOS ......................................................... 15

3.1 Tratamentos ................................................................. 15

3.2 Determinações ............................................................. 16

3.3 Análise sensorial ............................................................ 16

3.4 Delineamento experimental e Análise estatística .......................... 19

4 RESULTADOS E DISCUSSÃO ................................................... 21

5 CONCLUSÕES ............................................................... 46

REFERÊNCIAS BIBLIOGRÁFICAS .......................................... 48 


\title{
CONSERVAÇÃO REFRIGERADA DE TANGOR 'MURCOTT' TRATADA TERMICAMENTE
}

\author{
Autora: ANA HELENA DE FELÍCIO \\ Orientador: Prof. Dr. RICARDO ALFREDO KLUGE
}

\section{RESUMO}

O objetivo deste trabalho foi determinar o efeito de tratamentos térmicos com ou sem aplicação de fungicida sobre a qualidade e o potencial de armazenamento de tangores. O armazenamento refrigerado por longos períodos aumenta a incidência de danos por frio ("chilling") e a incidência de podridões em tangor 'Murcott'. As frutas foram submetidas a duas temperaturas de armazenamento: 1 e $4^{\circ} \mathrm{C}$, sendo que em cada uma delas os seguintes tratamentos foram aplicados: 1) Controle (frutas sem fungicida, apenas imersas em água a $25^{\circ} \mathrm{C}$ durante dois minutos); 2) Imersão das frutas em imazalil 50 $\left(\mathrm{mg} \mathrm{L}^{-1}\right)$ a $25^{\circ} \mathrm{C}$ por dois minutos; 3) Imersão das frutas em imazalil $50\left(\mathrm{mg} \mathrm{L}^{-1}\right)$ a $53^{\circ} \mathrm{C}$ por dois minutos; 4) Imersão das frutas apenas em água quente a $53^{\circ} \mathrm{C}$ por dois minutos. Todos os frutos tratados foram armazenados a 1 e $4^{\circ} \mathrm{C}$ por 8 semanas. As avaliações foram feitas a cada 2 semanas e foram determinadas as características físico-químicas e as características sensoriais. A redução na temperatura de armazenamento e os tratamentos térmicos tiveram pouca influência nas características físico-químicas. Os frutos armazenados a $1^{\circ} \mathrm{C}$ apresentaram desenvolvimento de sintomas de danos por frio a partir da sexta semana de armazenamento. Os frutos tratados termicamente antes do 
armazenamento apresentaram redução nos danos por frio, porém tiveram uma elevação na perda de massa. Não houve efeito da aplicação do fungicida na incidência de danos por frio e de podridões, tampouco nas características físico-químicas. As características sensoriais foram decrescendo ao longo do período, sendo que os frutos tratados terrmicamente e armazenados a $1^{\circ} \mathrm{C}$ apresentaram melhores caracterrísticas sensoriais ao final das avaliações. 


\title{
COLD STORAGE OF HEAT TREATED 'MURCOTT’ TANGOR
}

\author{
Author: ANA HELENA DE FELÍCIO \\ Adviser: Prof. Dr. RICARDO ALFREDO KLUGE
}

\section{SUMMARY}

The objective of this work was to determine the effect of heat treatment with or without fungicide on the quality and potential storage of 'Murcott' tangor. The cold storage for long time increases the incidence of chilling injury and decay of 'Murcott' tangor. Fruit were stored under two cold storage temperatures: 1 and $4^{\circ} \mathrm{C}$, and different treatments were applied in each one: 1) Control (fruit without fungicide, just with $25^{\circ} \mathrm{C}$ water dip/2min), 2) Fruit with $25^{\circ} \mathrm{C}$

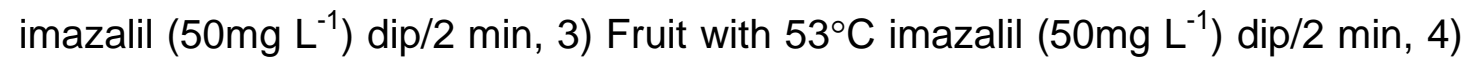
Fruit just with $53^{\circ} \mathrm{C}$ water dip/2min. All fruit were stored (under temperatures $1^{\circ} \mathrm{C}$ and $4^{\circ} \mathrm{C}$ ) during 8 weeks. Every two weeks analysis were determining the physico-chemicals properties and the sensorial characteristics. Reduction of storage temperature and heat treatments had low influence over physicochemicals properties. The $1^{\circ} \mathrm{C}$ stored fruit presented chilling injury symptoms after 6 weeks. The heat treated fruit before storage showed reduction on chilling injury levels but increased weight loss. The fungicide dips did not have effects over chilling injury and decay incidence neither on physico-chemicals properties. The sensorial characteristics decreased along the period. Heat treated and $1^{\circ} \mathrm{C}$ stored tangor 'Murcott` presented better on the sensorial evaluations. 


\section{INTRODUÇÃO}

Estimativas recentes indicam que as perdas pós-colheita no Brasil atingem índices de 30 a 40\% da produção de frutas e hortaliças (FNP, Consultoria e Comércio, 2000). Vários fatores contribuem para este quadro desalentador, incluindo colheita e transporte inadequados, falta da cadeia de frio ou utilização inadequada da mesma, embalagens impróprias, entre outros.

Outra causa de perdas decorre da rejeição por parte do consumidor que, embora intuitivamente, valoriza aspectos como aparência, (tamanho, forma, ausência de defeitos e cor), sabor, aroma e textura. Como boa parte desses atributos de qualidade sofre alterações físico-químicas e bioquímicas após a colheita é preciso buscar a redução da atividade metabólica, uma vez que essa atividade provoca perda de massa, alteração de textura, aroma, aparência e do valor nutritivo (Nunes, 2003).

A refrigeração tem sido a principal técnica utilizada para preservar a qualidade dos produtos hortifrutícolas recém colhidos. Para as frutas cítricas, o controle de podridões é um dos aspectos de maior importância no mercado de frutas destinadas ao consumo in natura. Assim, o uso de baixa temperatura de armazenamento é importante para retardar o desenvolvimento das podridões e prolongar o período de oferta de citros no mercado. Entretanto, dada a sensibilidade dos citros à baixa temperatura, o seu armazenamento por longos períodos é dificultado, considerando que, invariavelmente, os sintomas de danos por frio surgem durante a fase de comercialização, após a retirada do produto da condição refrigerada. 
Assim, com o objetivo de manter os benefícios da refrigeração e evitar os danos por frio, técnicas complementares vêm sendo testadas. Dentre essas técnicas temos o tratamento térmico, que consiste no acondicionamento do produto em temperatura alta ou moderada antes da refrigeração. Em nível comercial, esse método tem sido pouco utilizado, devido ao baixo conhecimento dos procedimentos de aplicação e do potencial de aumento de conservação em relação ao armazenamento convencional.

Os tratamentos térmicos têm sido considerados como promissores tratamentos não químicos para controlar o desenvolvimento de patógenos em frutas cítricas. Além disso, esses tratamentos podem permitir o armazenamento do produto em temperatura menor do que aquela recomendada, considerando que ocorre um aumento na resistência às baixas temperaturas quando as frutas são tratadas termicamente. A origem desta resistência ainda não é bem conhecida.

O presente trabalho teve por objetivo determinar 0 efeito do condicionamento térmico, associados ou não ao fungicida sobre a qualidade e o desenvolvimento de sintomas de danos por frio em tangor 'Murcott' durante o armazenamento. 


\section{REVISÃO DE LITERATURA}

\subsection{Aspectos gerais sobre tangor 'Murcott`}

O tangor 'Murcott' pertence à Família Rutaceae, sendo um híbrido de tangerina (Citrus reticulata Blanco) com laranja doce (Citrus sinensis L. Osb.). Foi originado de um pomar abandonado do Departamento de Agricultura dos Estados Unidos (USDA) nas proximidades de Miami, Flórida, e propagado pela primeira vez por Charles Murcott Smith. Suas árvores e frutos possuem diversas características de uma tangerina típica, tais como: alto vigor, hábito de crescimento ereto e folhas lanceoladas entre outras (Davies \& Albrigo, 1994).

Seus frutos são de tamanho médio, massa média de $140 \mathrm{~g}$, cerca de 20 sementes por fruto, formato achatado, com uma pequena cavidade no seu eixo central. Sua casca, quando o fruto está maduro, é de cor laranja vivo, com espessura fina, aderente e com glândulas de óleo em nível; a polpa é de cor laranja vivo e sua textura é firme; seu suco é abundante, representando cerca de $48 \%$ da massa do fruto, com teor de sólidos solúveis de $12,6^{\circ}$ Brix e $0,92 \%$ de acidez titulável (Davies \& Albrigo, 1994 e Figueiredo, 1991).

O fruto típico do citros é o hesperídeo, com casca formada por duas partes distintas - o albedo e o flavedo. O albedo é a parte mais espessa do mesocarpo, de cor branca, e o flavedo é a parte mais externa, rica em glândulas de óleos essenciais. Internamente o fruto é dividido em diversos segmentos, chamados comumente de gomos. Os segmentos, revestidos por finas paredes membranosas, contêm as vesículas de suco e as sementes. O suco das vesículas contém açúcares, ácidos orgânicos, sais minerais, enzimas, carotenos e licopenos (Koller, 1994). 
As variedades comerciais de tangerina mais cultivadas no país são as tangerinas 'Poncã”, 'Murcott', 'Cravo' e 'Mexerica', que são responsáveis por cerca de $62 \%, 20 \%, 11 \%$ e $8 \%$, respectivamente, da produção de frutos no grupo das tangerineiras (Figueiredo, 1991; Camargo et al., 2002). A tangerina 'Poncã' tem uma vantagem em relação ao tangor 'Murcott' que é a sua facilidade no descascamento. Ao contrário, o tangor apresenta casca relativamente fina e bastante aderida.

A produção brasileira de 'Murcott' é destinada aos mercados interno e externo para o consumo in natura (Figueiredo, 1991). Entre os anos de $1998 \mathrm{e}$ 2001 houve um aumento de cerca de 18\% do volume de 'Murcott' comercializado no Ceagesp - SP e, no mesmo período, verificou-se queda de $18,75 \%$ no preço deste produto, que teve 22.240 toneladas de produto comercializadas naquele entreposto (FNP Consultoria e Comércio, 2005).

Embora o tangor 'Murcott' seja a variedade mais exportada, devido às suas qualidades organolépticas e boa aceitação no mercado, os valores exportados de tangerinas representam apenas 3\% da produção nacional (Amaro e Case, 2003).

A 'Murcott' é um fruto de maturação tardia. No Brasil, o pico de sua produção ocorre entre os meses de agosto a novembro (Figueiredo, 1991), sendo uma das últimas tangerinas a entrar no mercado. Apesar de não ser a tangerina preferida no mercado brasileiro, sua qualidade interna está entre as melhores entre as tangerinas e seus híbridos. Sua casca e suco adquirem coloração alaranjada intensa no seu ponto ótimo de maturação, sendo bastante atrativa (Davies \& Albrigo, 1994).

Um dos fatores determinantes na longevidade das frutas na pós-colheita é o tipo de padrão respiratório apresentado por ela. O tangor 'Murcott' é um fruto não climatérico, pois apresenta declínio constante na taxa respiratória em função do tempo. 


\subsection{Armazenamento refrigerado}

A refrigeração tem sido a técnica pós-colheita mais utilizada para a preservação de frutas frescas, considerando que ela reduz o metabolismo, diminui a perda de massa, retarda o desenvolvimento de patógenos causadores de podridões e atrasa a senescência (Hardenburg et al., 1986; Chitarra \& Chitarra, 1990).

Baixas temperaturas de armazenamento são convenientes, pois contribuem para a redução do metabolismo e também das taxas respiratórias. Mas elas fazem com que outras reações, mais sensíveis a baixas temperaturas, ocorram, caso seja atingida uma temperatura crítica. Dessa forma, pode ocorrer desequilíbrio no metabolismo, levando à manifestação de distúrbios fisiológicos (Wills et al., 1998).

Cada fruta e variedade apresenta uma temperatura ótima de conservação e um período máximo de conservação sob tais condições. Segundo dados de literatura, as condições ótimas para a conservação refrigerada de tangerinas é de 4 a $7^{\circ} \mathrm{C}$ e $90-95 \%$ UR, com as frutas podendo ser armazenadas nestas condições por 2 a 4 semanas, dependendo da variedade (Hardenburg et al., 1986; ASHRAE, 1994; Cantwell, 2001).

Um outro problema na limitação da vida pós-colheita de frutas cítricas que pode ser amenizado com o armazenamento refrigerado é o aparecimento de podridões (Kader, 1985). A temperatura mínima para desenvolvimento de fungos in vitro é entre $4^{\circ}$ e $5^{\circ} \mathrm{C}$. Nessa temperatura, as frutas cítricas não tratadas com fungicidas podem desenvolver de 25 a 50\% de podridões (Cohen, 1990; Guerra et al, 1990; Porat et al., 2000a).

\subsection{Danos por frio}

A maioria dos produtos hortícolas são sensíveis ao frio, porém, essa sensibilidade pode ser subdividida em 3 categorias: resistentes ao "chilling", 
sensíveis ao "chilling" e pouco sensíveis ao "chilling". Na primeira, quanto mais baixa for a temperatura, maior será a vida útil do produto, contanto que não atinja o ponto de congelamento. Entretanto, nos outros dois grupos isso já não é real, pois a partir de um determinado ponto chamado de temperatura crítica ou temperatura mínima de segurança (TMS), a vida útil também começa a diminuir (Wang, 1994b).

A TMS varia de acordo com o produto e a variedade mas situa-se em uma faixa que vai de 0 a $15^{\circ} \mathrm{C}$. Ela define a faixa de temperatura e o tempo de exposição dos produtos para que os danos comecem a ocorrer. Apesar das células não congelarem, a exposição dos frutos a baixas temperaturas por um tempo prolongado pode causar várias alterações metabólicas, reduzindo, portanto, a qualidade (Markhart III, 1986 e Bron et al., 2002).

As frutas cítricas em geral são sensíveis a baixas temperatura. A desordem fisiológica de maior relevância quanto à qualidade do produto, com impacto no seu valor comercial, é o dano por frio, também denominado injúria pelo frio ou "chilling injury" em inglês. Os danos por frio ocorrem durante o armazenamento sob temperatura abaixo da TMS e os sintomas se manifestam, normalmente, durante a exposição à temperatura ambiente, durante a comercialização (Chitarra \& Chitarra, 1990; Schirra et al., 1997a; Hardenburg et al., 1986) alertam que temperaturas entre 0 a $1^{\circ} \mathrm{C}$ podem ser utilizadas para tangerinas, mas não por mais do que 2 semanas, sob o risco de surgirem injúrias pelo frio durante a comercialização. Arras \& Usai (1991) verificaram que tangores 'Murcott' sofreram danos por frio após 18 dias a $2^{\circ} \mathrm{C}$.

Nos frutos em geral, os sintomas de danos por frio podem se manifestar como escurecimento interno, depressões superficiais externas, falha no amadurecimento, polpa translúcida, dificuldade no desenvolvimento normal da cor da polpa e perda de sabor e aroma característicos (Kluge et al., 2002). Esses sintomas ocorrem nos frutos em geral, porém alguns apresentam sintomas específicos como no caso de escurecimento interno em batatas e manchas na membrana em limões (Wang, 1994b). 
O primeiro evento que acontece durante a exposição de um fruto a temperatura abaixo da TMS é a alteração da membrana celular que passa do estado de líquida cristalina para gel-sólida, mudando assim a sua estrutura e permeabilidade, podendo acontecer alterações metabólicas. Após, ocorrem os eventos secundários como a estimulação da produção de etileno, aumento da taxa respiratória e aparecimento de sintomas de distúrbios fisiológicos (Wang, 1982).

O desenvolvimento de danos por frio aumenta a produção de ACC e de etileno, o que diminui a resistência dos frutos aos patógenos causadores de podridões, além de provocar o amadurecimento irregular. Outra resposta é o aumento da aividade das enzimas oxidativas, como a polifenoloxidase (PPO), a peroxidase (POD) e a fenilalanina amonia-liase (PAL),envolvidas na manifestação dos danos por frio (Siegel \& Siegel, 1986; Cohen et al., 1988; Parking et al., 1989).

A POD é a enzima antioxidante responsável pelo catabolismo de peróxido $\left(\mathrm{H}_{2} \mathrm{O}_{2}\right)$. Se esse mecanismo não estiver operando corretamente, espécies ativas de $\mathrm{O}_{2}$ passam a induzir a peroxidação de lipídeos e a alterar a deterioração de membranas. Baixas temperaturas podem gerar o acúmulo excessivo de espécies de $\mathrm{O}_{2}$, então a POD não remove o $\mathrm{O}_{2}$ formado, mas sim reage com o peróxido para impedir o aumento de oxigênio. Portanto, a POD é uma enzima que mantém o nível de oxigênio baixo. Quando exposta ao frio a POD deixa de metabolizar $0 \mathrm{H}_{2} \mathrm{O}_{2}$, passando os frutos a apresentar sintomas de "chilling" (Lurie, 2003).

A PPO é a enzima responsável pelo escurecimento através de seu contato com o ar e compostos fenólicos. Primeiramente os fenóis reagem com a PPO formando o-quinona, que ao reagir com outros compostos fenólicos e aminoácidos e proteínas produzindo pigmentos escuros. A PPO encontra-se nas membranas dos plastídeos e nas mitocôndrias e os polifenóis no vacúolo. Com o frio há um maior contato das enzimas com o substrato, conduzindo ao escurecimento, pois ocorre um aumento de permeabilidade da membrana. 
A POD e a PPO têm sido consideradas as principais enzimas responsáveis pela deterioração da qualidade em muitos frutos. Estas enzimas podem participar de um grande número de reações oxidativas e de biodegradação, tais como mudança de cor, degradação da clorofila ou auxinas, oxidação de fenóis, biossíntese de lignina. Muitos destes fatores também podem ser associados com "flavour", cor, textura e qualidade nutricional dos alimentos (Valderama et al., 2001).

A PAL é a principal enzima do metabolismo secundário, que é aquele responsável pelo mecanismo de defesa nas plantas. Ela atua primeiramente na via de formação dos compostos fenólicos e é ativada por fatores ambientais como: baixos níveis de nutrientes, luz e ataque de patógenos. Os danos por frio aumentam a concentração de fenóis devido ao aumento na atividade da PAL (Forney, 2003). O frio pode diminuir as chances da enzima se solubilizar. O aumento da atividade da PAL tem sido associado ao aumento do etileno endógeno em diferentes tecidos vegetais, inclusive em casca de citros (Martínez-Téllez \& Lafuente, 1997).

\subsection{Métodos de controle de danos por frio}

Praticamente não existe um método que possa evitar completamente os danos por frio. O método mais aplicado é o armazenamento das frutas em temperaturas adequadas, acima da TMS (Kluge et al., 2002), mas nem sempre isso é suficiente. Nesses casos, métodos alternativos vêm sendo testados para aumentar a tolerância das frutas aos danos de frio. Esses métodos incluem o aquecimento intermitente, o condicionamento térmico e a atmosfera controlada.

$\mathrm{O}$ aquecimento intermitente consiste em interromper o armazenamento a baixas temperaturas, substituindo-o, por um ou mais períodos por temperaturas mais altas. Esse procedimento deve ser realizado antes que os danos se tornem irrreversíveis, variando esse limite de acordo com o produto (Kluge et al., 2002). O aquecimento intermitente foi utilizado no controle de danos por frio 
em limão (Artés \& Escricher, 1994), pêssego (Kluge et al., 1996), pepinos e abobrinha (Wang, 1994a).

O condicionamento térmico consiste em expor as frutas a temperaturas moderadas ou elevadas, por curtos períodos, antes de refrigerá-las. O uso desta técnica resulta, basicamente, no retardamento da senescência, na diminuição dos danos causados pelas baixas temperaturas e na redução de podridões (Kluge et al., 2001). Ferguson et al. (2000) relatam redução dos sintomas como o escurecimento da casca, pintas e depressões a casca em citros quando da aplicação do condicionamento térmico.

Em frutos climatéricos o tratamento térmico tem como principais conseqüências o retardamento do amadurecimento, pois reduz a síntese de etileno e a atividade das enzimas que degradam a parede celular, a diminuição dos danos causados pelas baixas temperaturas e a redução de podridões (Klein \& Lurie, 1991; Kluge et al., 2002).

O tratamento térmico tem se mostrado útil para diminuir podridões em citros e reduzir a sensibilidade desses frutos aos danos por frio. Porém, esses efeitos têm sido observados numa faixa estreita de temperatura, provavelmente em decorrência da combinação de dois fatores: inibição de patógenos pelo calor e danos de fitotoxicidade das frutas (Ben-Yehoshua et al., 2000).

O condicionamento em temperatura moderada $\left(15-25^{\circ} \mathrm{C}\right)$ reduziu as injúrias pelo frio em mamão, manga, pimentão, abobrinha e limão (Kluge et al., 2002) e também têm sido utilizadas temperaturas elevadas, entre $35^{\circ}$ e $60^{\circ} \mathrm{C}$ (Artès, 1995). Em casas de embalagens de vários tipos de citros foi utilizada água em temperatura entre $51^{\circ}$ e $54^{\circ} \mathrm{C}$, por aproximadamente 2 minutos, conseguindo-se redução significativa do índice de podridões. Já para frutos tratados em água à temperatura de $57^{\circ} \mathrm{C}$ observou-se uma descoloração marrom na casca (Ben-Yehoshua et al., 2000).

O condicionamento em altas temperaturas (30 a $60^{\circ} \mathrm{C}$ ) por curtos períodos mostrou-se eficiente na diminuição dos danos por frio em melancia, mamão (Chan \& Forbus, 1988), pêssegos (Nanos \& Mitchell, 1991), abobrinha, 
maçã (Lurie \& Klein, 1990), tomate (Lurie \& Klein, 1991), pepino (McCollum et al., 1993), abacate (Woolf \& Lay-Yee, 1985) e pimentão (González-Aguilar et al., 2000).

O aquecimento a $34-36^{\circ} \mathrm{C}$ durante 48 a 72 horas (curing) tem controlado efetivamente o desenvolvimento de podridões e reduzido os sintomas de danos por frio em frutas cítricas armazenadas sob refrigeração (Ben-Yehoshua et al., 1987; Del Rio et al., 1992). Rodov et al. (2000) destacam que o curing apresenta dificuldade de implantação ao nível comercial, devido à longa duração do tratamento sob alta temperatura, o que favorece a desidratação das frutas. Alguns autores destacam que períodos menores de tratamento (2 a 3 minutos), porém em temperaturas superiores (50 a $53^{\circ} \mathrm{C}$ ), podem evitar a desidratação e, ao mesmo tempo, reduzir a incidência de podridões e a sensibilidade das frutas à temperaturas subótimas (Schirra \& Mulas, 1993; Rodov et al., 1995 e 2000).

Os tratamentos térmicos em frutos são também úteis na desinfecção de insetos, no controle de patógenos, para mudança de resposta dos frutos ao estresse e na manutenção da qualidade durante o armazenamento (Paul \& Chen, 2000). Uma das formas de ação é a mudança na casca do fruto. O tratamento pode ocasionar o fechamento de pequenas fissuras na cutícula protegendo assim o fruto de infestações por patógenos. Estudos a respeito de qual o efeito direto em fungos ainda estão sendo realizados (Ferguson et al., 2000). Pimenta vermelha doce tratada em água a $50^{\circ} \mathrm{C}$ por 3 minutos apresentou redução significativa em podridões causadas por Botrytis cinerea Alternaria alternata (Fallik et al., 1999).

Lafuente et al. (2001), relatam que a indução de PAL durante o armazenamento, e não antes dele, podem reduzir o desenvolvimento dos sintomas de danos por frio.

Os tratamentos térmicos comercialmente utilizados (temperatura elevada por curto tempo), são pouco efetivos para uma inativação irreversível principalmente da peroxidase (Valderama et al., 2001). 


\subsection{Tratamentos químicos associados ao armazenamento}

A suscetibilidade a doenças em frutos frescos colhidos aumenta durante o período de armazenamento, como resultado das mudanças fisiológicas que ocorrem tornando-o mais propício à infestação por patógenos (Fallik et al., 2000).

Injúrias causadas em citros durante a colheita facilitam a entrada de patógenos, incluindo o Penicillium digitatum Sacc (bolor verde) e Penicillium italicum Wehmer (bolor azul). Essses patógenos ocorrem em quase todos os lugares do mundo onde os citros são cultivados (Korsten et al., 2000). Fungicidas sintéticos têm sido o principal método utilizado para controle de podridões pós-colheita de citros. Além da preocupação com a saúde humana, existe também o problema do uso contínuo destes pesticidas proliferarem espécies existentes desses patógenos (Obagwu \& Korsten, 2003).

A demanda por produtos cítricos orgânicos tem crescido apreciavelmente devido à crescente preocupação com a qualidade dos alimentos e com a ausência de resíduos químicos. Porém, durante a estocagem os produtos orgânicos sofrem grandes perdas por podridões, que alcançam médias de 30 a $50 \%$ nos cultivares susceptíveis de citros, sendo este o maior limitante para a expansão dos citros orgânicos. Por outro lado, as restrições fitossanitárias impostas pelos Estados Unidos continuam a restringir ou impedir as exportações de tangerinas com uso de pesticidas - do Brasil e de outros países produtores (Amaro e Caser, 2003).

Imazalil (IMZ), tiabendazol (TBZ), benomil, tiofanato metil e carbendazim são fungicidas comumente usados para controlar podridões pós-colheita de citros. Porém, a monitorização de seus resíduos tem se tornado indispensável (Fernández et al., 2001).

Até 1955 , melões eram tratados nas casas de embalagens com uma cera contendo $2000 \mu \mathrm{L} \mathrm{L}^{-1}$ de IMZ que reduziram as podridões durante 0 
armazenamento. Entretanto, este tratamento deixa um resíduo de $3-5 \mu \mathrm{L} \mathrm{L}^{-1}$ por fruta, quando a quantidade máxima permitida é de $0,5 \mu \mathrm{L} \mathrm{L}^{-1}$ (Fallik et al., 2000). Pomelos 'Star Ruby' são suscetíveis a baixas temperaturas de estocagem, e condições de quarentena costumam provocar danos por frio. Tratamentos térmicos na pós-colheita e alguns fungicidas como TBZ e IMZ induzem a tolerância dos citros sensíveis ao frio. Esses fungicidas tornam-se ainda mais eficientes quando seu uso é associado ao condicionamento térmico (Shirra et al., 2000).

Testes foram realizados procurando a união de tratamento térmico e a aplicação de fungicida para redução de antracnose em citros. Os tratamentos realizados com fungicidas e imersão em água à $53^{\circ} \mathrm{C}$ apresentaram melhor resultado que aqueles realizados a temperatura ambiente (Wild \& Hood, 1989). A utilização de tratamento térmico (com e sem fungicida) promove redução dos riscos ambientais e aumenta a qualidade de vida humana (Hara et al., 1995). A aplicação de escovação por 20 segundos com água a $62^{\circ} \mathrm{C}$, a imersão em banho de bicarbonato de sódio (SBC), ou controle biológico, realizado com Candida oleophila, 24 horas depois da infestação de pomelos 'Star Ruby' por Penicillium digitatum, reduziu o índice de podridões em 68, 61 e 23\%, respectivamente. A combinação de dois quaisquer dos tratamentos acima mencionados, ou até mesmo a utilização dos três tem uma eficiência de 80 85\% comparável à do IMZ, de 95\% (Porat et al., 2002).

O tratamento térmico utilizado juntamente com IMZ em citros apresenta bons resultados em relação ao fungicida sem aquecimento. Em conseqüência, pode-se diminuir a dosagem de aplicação de fungicidas de $1000 \mathrm{mg} \mathrm{L}^{-1}$ para $400 \mathrm{mg} \mathrm{L}^{-1}$ (Ben-Yehoshua et al., 2000). Schirra et al. (1997b), trabalhando com limões 'Di Massa', observaram menor incidência de podridões causadas por Penicillium spp. ao submeterem os frutos durante 3 minutos a uma solução aquecida a $50^{\circ} \mathrm{C}$ de IMZ (50 $\left.\mathrm{mg} \mathrm{L}^{-1}\right)$. Segundo os autores, esse tratamento é eficiente para longos períodos de armazenamento de limões, considerando que além da redução de podridões, atrasou o amarelecimento dos frutos. Segundo 
os mesmos autores, o aumento da eficiência dos fungicidas sobre podridões, quando aplicados em combinação com água quente, está relacionado com o efeito exercido pelo calor no aumento da cobertura e penetração do ingrediente ativo no fruto.

\subsection{Efeitos fisiológicos e bioquímicos dos tratamentos térmicos}

Os efeitos dos tratamentos térmicos sobre a fisiologia, bioquímica e a qualidade dos produtos são pouco conhecidos e uma vez estabelecidos, podem ajudar a identificar processos metabólicos passíveis de manipulação, proporcionando a criação de tecnologias de armazenamento que permitam o aumento da vida útil dos frutos.

Estudos mostram que os tratamentos térmicos podem manter a estabilidade da membrana celular e suprimir a atividade das enzimas oxidativas, como POD, PPO e PAL, fazendo o fruto suportar baixas temperaturas por mais tempo (Wang, 1993).

Lurie \& Klein (1990 e 1991) observaram que o condicionamento térmico induz a produção de proteínas de choque de calor (HSP-"heat shock protein"), que parecem estar envolvidas no processo de termotolerância. Embora comprovada, a produção de HSP não é a única resposta dos frutos submetidos aos tratamentos térmicos. O tratamento térmico pode também inibir temporariamente a síntese de enzimas como, por exemplo, a ACC sintase responsável pela produção de ACC, precursor imediato do etileno. Dessa forma atrasa o pico de produção do etileno, reduzindo a velocidade de amadurecimento em frutos climatéricos (Zhou et al., 2002). Em frutos não climatéricos, como o citros, ainda não se conhece o envolvimento do etileno na manifestação ou na resistências de danos por frio.

Uma possível resposta para o efeito dos tratamentos térmicos está nas poliaminas. Elas podem atuar inibindo vários processos metabólicos, relacionados com a senescência dos tecidos vegetais, tais como a atividade de 
enzimas degenerativas (poligalagturonase, proteases e ribonucleases) ou a peroxidação de lipídeos (atividade antioxidante). Além disso, podem estabilizar a estrutura das membranas (Artés, 1995). As poliaminas também podem ser responsáveis pela resistência dos frutos aos danos por frio.

Os tratamentos térmicos podem incrementar a tolerância dos produtos às baixas temperaturas e também aumentar o período de armazenamento. Entretanto, não só o conhecimento dos efeitos dos tratamentos térmicos no controle de danos por frio é importante, mas também a viabilidade prática e econômica da técnica que, uma vez estabelecida, pode tornar esse tipo de tratamento aplicável comercialmente.

Os tratamentos térmicos podem se tornar um poderoso aliado na ampliação do consumo de frutas cítricas orgânicas. Como esses produtos não podem receber tratamentos com fungicidas acabam apresentando um alto índice de podridões (Porat et al., 2000b). 


\section{MATERIAL E MÉTODOS}

Tangores 'Murcott' (Citrus reticulata Blanco $x$ Citrus sinensis Osbeck) colhidos na região de Engenheiro Coelho (SP), durante a safra de 2004, foram transportados para o Laboratório de Pós-Colheita do Departamento de Produção Vegetal, ESALQ/USP, em Piracicaba, SP.

As frutas foram submetidas à seleção para composição de um lote uniforme, com tamanho médio, sem defeitos com ausência de patógenos. Em seguida as frutas foram lavadas contendo cloro $200 \mathrm{mg} \mathrm{L}^{-1} \mathrm{e}$, posteriormente secadas.

\subsection{Tratamentos}

As frutas foram submetidas a duas temperaturas de armazenamento: $1 \mathrm{e}$ $4{ }^{\circ} \mathrm{C}$, sendo que em cada uma delas os seguintes tratamentos foram aplicados: 1) Controle (frutas sem fungicida, apenas imersas em água a $25^{\circ} \mathrm{C}$ durante dois minutos); 2) Imersão das frutas em imazalil $50 \mathrm{mg} \mathrm{L}^{-1}$ a $25^{\circ} \mathrm{C}$ por dois minutos; 3) Imersão das frutas em imazalil $50 \mathrm{mg} \mathrm{L}^{-1}$ a $53{ }^{\circ} \mathrm{C}$ por dois minutos; 4) Imersão das frutas apenas em água quente a $53^{\circ} \mathrm{C}$ por dois minutos. Para os tratamentos com aquecimento das soluções foi utilizado um banho térmico para frutas, marca Tecnal. 


\subsection{Armazenamento dos frutos}

Os frutos foram armazenados em câmaras frias do Laboratório de PósColheita do Departamento de Produção Vegetal, ESALQ/USP, Piracicaba-SP. O período total de armazenamento das frutas foi de 8 semanas e as avaliações feitas a cada 2 semanas, sendo que os frutos depois de retirados foram submetidos a uma comercialização simulada de 4 dias a $25^{\circ} \mathrm{C}$, para avaliar 0 efeito dos tratamentos na sua vida de prateleira.

\subsection{Determinações}

As seguintes determinações foram realizadas:

a) Coloração da casca

A coloração da casca foi determinada utilizando a metodologia de McGuirre (1992), através do aparelho Minolta Chroma Meter CR-300. Foram medidos os valores de ângulo de cor $\left(\mathrm{h}^{\circ}\right)$ e croma (C). Foram realizadas duas leituras por fruta em dois pontos diferentes.

b) Teor de sólidos solúveis (SST)

Foi determinado em refratômetro digital, com correção automática de temperatura para $20^{\circ} \mathrm{C}$ e os resultados expressos em ${ }^{\circ}$ Brix.

c) Acidez titulável (AT) 
Para se determinar a AT foram colocados $10 \mathrm{~mL}$ do suco em $90 \mathrm{~mL}$ de água destilada. Depois foi realizada a titulação potênciométrica usando $\mathrm{NaOH}$ $0,1 \mathrm{~N}$ até $\mathrm{pH} 8,10$. Os resultados foram expressos em \% ácido cítrico.

d) "Ratio"

Foi calculado a partir da divisão do teor de SST pela AT.

e) Teor de Ácido Ascoórbico

O teor de ácido ascórbico foi determinado a partir da metodologia de Carvalho et al. (1990). Esta metodologia baseia-se na redução do indicador 2,6 diclorofenol indofenol-sódio (DCFI) pelo ácido ascórbico. Foram obtidos 10mL da amostra e colocados em erlenmeyer com $50 \mathrm{~mL}$ de ácido oxálico. A titulação foi realizada com DCFI até que a solução tome uma cor rosada. Os resultados então são expressos em mg de ácido ascórbico/100mL.

f) Perda de massa

A perda de massa foi calculada através da diferença em porcentagem, da massa inicial e final verificada após o armazenamento.

g) Danos por frio

Os danos causados pela baixa temperatura foram determinados através da porcentagem de frutos afetada em cada repetição e da severidade desses danos. A severidade foi avaliada através da área da casca que foi afetada. As frutas podem ser classificadas da seguinte forma: $1=0 \%$; $2=<5 \%$; $3=5-25 \%$; $4=25-50 \%$ e $5=>50 \%$ da área afetada. 
h) Incidência de podridão

Foram determinadas a porcentagem de frutas afetadas por repetição e a severidade de podridões. Os patógenos causadores das podridões foram identificados no Laboratório de Fitopatologia da ESALQ. Dependendo da área afetada as frutas foram classificadas em cinco categorias: $1=0 \% ; 2=<5 \%$; $3=$ 5-25\%; 4 = 25-50\% e 5 = > 50\% da área afetada.

i) Análise sensorial

As características sensoriais das frutas foram determinadas na caracterização do lote experimental e após cada período de armazenamento (mais 4 dias de comercialização simulada). Cada tratamento foi representado por uma amostra de 4 frutas (uma de cada repetição). As avaliações foram realizadas por uma equipe constituída de 21 provadores, sendo eles técnicos de laboratórios e estagiários do Departamentos de Ciências Biológicas e Produção Vegetal. Para composição da equipe foram selecionadas pessoas não fumantes, com habilidade para detectar variações nos atributos de qualidade de tangerina e com disponibilidade de horário nas datas previamente agendadas. Antes do início do experimento, os provadores foram familiarizados com as definições das escalas, mediante várias sessões de treinamento.

As seguintes escalas foram utilizadas:

odor estranho: foi utilizada uma escala de notas de 1 a 5 , onde 1 = isento; 2 = ligeiro; 3 = moderado; 4 = intenso e 5 = muito intenso.

sabor estranho: foi adotada metodologia semelhante àquela utilizada para odor estranho.

qualidade global: as notas foram atribuídas considerando-se a presença de fatores que depreciam a qualidade da fruta como: odor e sabor estranhos, perda de brilho, murchamento, amassamento, podridões e sobrematuração. A ausência desses fatores implicou em atribuição de nota máxima para a amostra 
(ótima) e a presença de um ou vários deles a ponto de caracterizar a amostra como inadequada para comercialização, implicou em atribuição da pior nota (péssima). Para medir a intensidade de cada atributo, foi utilizada a escala de 1 a 5 , onde 1 = péssima; 2 = ruim; 3 = razoável; 4 = boa e $5=$ ótima .

Os resultados das avaliações foram anotados em fichas apropriadas, tabulados e analisados.

\subsection{Delineamento experimental e análise estatística}

O delineamento experimental foi inteiramente ao acaso, em esquema fatorial $4 \times 5$ para cada temperatura. Os fatores estudados foram tratamento, em 4 níveis, e período de avaliação, em 5 níveis (incluindo o tempo zero). Foram utilizadas 4 repetições de 10 frutas. Para a caracterização do lote experimental foram utilizadas 4 parcelas de 10 frutas. 
NOME:

NOTA : Use as seguintes escalas para avaliar os diferentes atributos:

\section{Sabor e Odor}

$1=$ isento

2 = ligeiro

$3=$ moderado

$4=$ intenso

$5=$ muito intenso

AMOSTRA $\mathbf{N}^{\circ} 1$

Sabor

Odor

Avaliação Global

AMOSTRA $\mathbf{N}^{\circ} 2$

Sabor

Odor

Avaliação Global

AMOSTRA $\mathbf{N}^{\circ} 3$

Sabor

Odor

Avaliação Global

AMOSTRA $N^{\circ} 4$

Sabor

Odor

Avaliação Global

\section{Avaliação Global}

$1=$ péssima

2 = ruim

$3=$ razoável

$4=$ boa

5 = ótima

Nota:

Nota:

Nota:

Nota:

Nota:

Nota:

Nota:

Nota:

Nota:

Nota:

Nota:

Nota:

Figura 1 - Ficha utilizada na análse sensorial 


\section{RESULTADOS E DISCUSSÃO}

Os tempos requeridos para as frutas atingirem as temperaturas de $1^{\circ} \mathrm{C} \mathrm{e}$

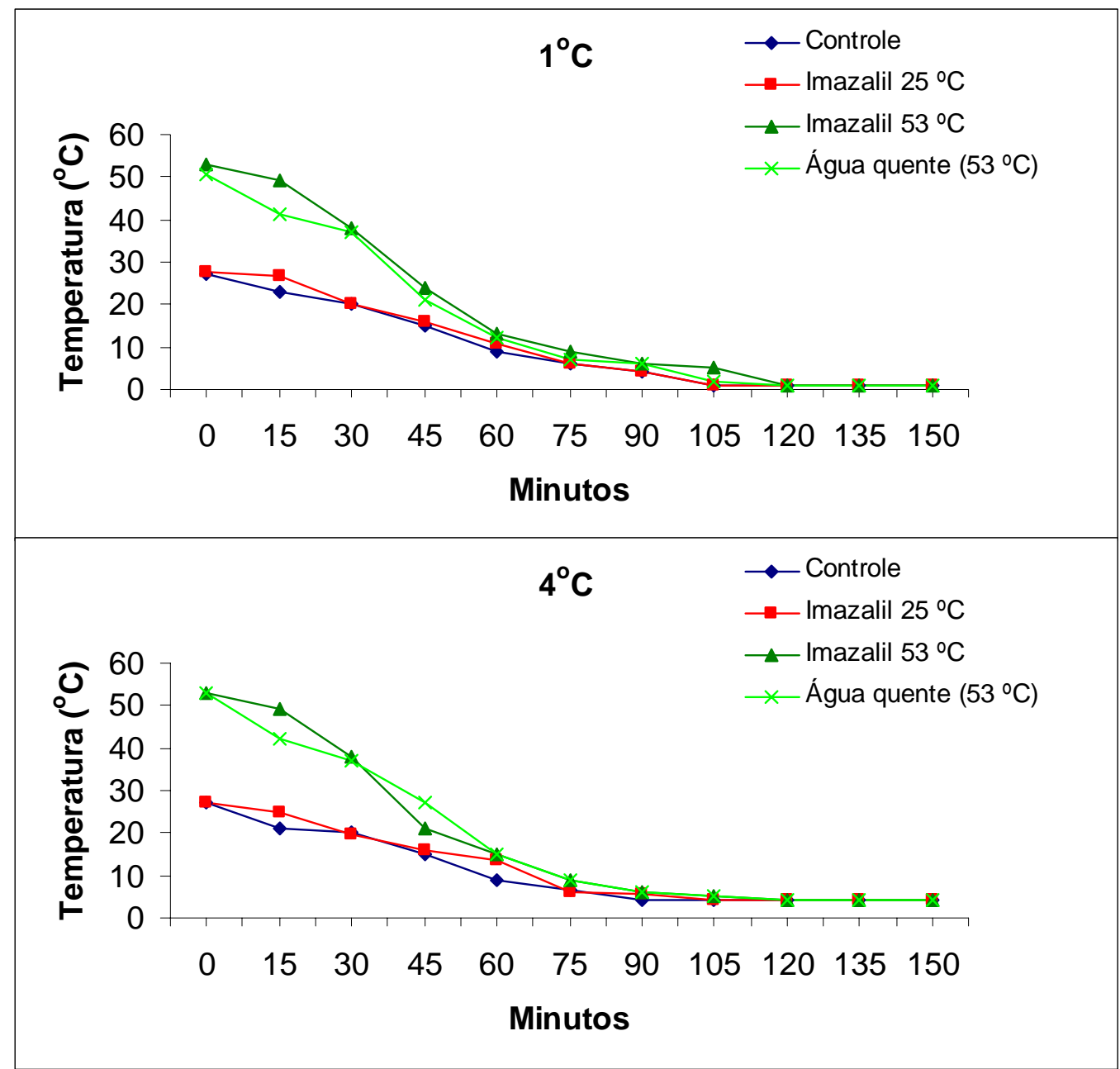

Figura 2 - Temperatura interna de tangor 'Murcott' após a colocação das frutas no armazenamento refrigerado 
$4^{\circ} \mathrm{C}$, após os tratamentos, foram medidos com termômetro de polpa e foram de aproximadamente 120 minutos para o armazenamento a $1^{\circ} \mathrm{C}$ e 90 minutos para o armazenamento a $4^{\circ} \mathrm{C}$ (Figura 2). Sabe-se que quanto mais rapidamente a fruta atingir a temperatura desejada menores são as perdas pós-colheita (ASHRAE, 1994; Cortez et al., 2002). Frutas que sofreram aquecimento, com ou sem fungicida, demoraram mais para atingirem a temperatura adequada, refletindo numa maior perda de massa dos frutos.

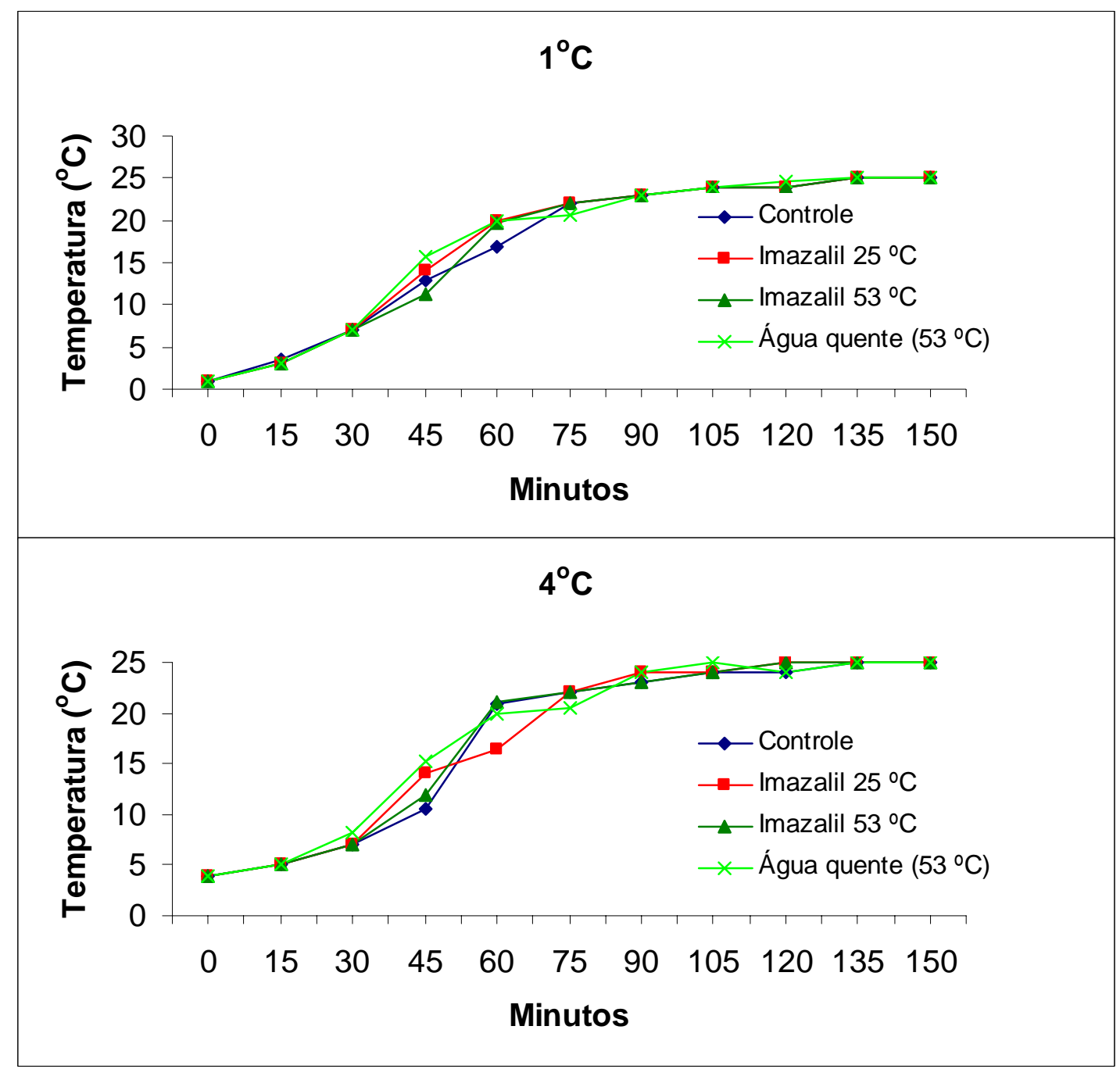

Figura 3 - Temperatura interna de tangor 'Murcott' após a retirada das frutas da condição refrigerada 
As frutas armazenadas a $4^{\circ} \mathrm{C}$ levaram 105 minutos para atingir a temperatura ambiente $\left(25^{\circ} \mathrm{C}\right)$ após a retirada da câmara, enquanto aquelas armazenadas a $1^{\circ} \mathrm{C}$ levaram 135 minutos. Observou-se então o que era esperado: as frutas armazenadas em temperaturas mais baixas levaram um tempo maior (30 minutos) para atingir a temperatura ambiente (Figura 3).

Após o período de comercialização simulada, os frutos armazenados a $1^{\circ} \mathrm{C}$ apresentaram danos por frio a partir da sexta semana de armazenamento. Esses danos foram caracterizados, principalmente, por depressões superficiais necróticas na casca (Figura 4), de coloração avermelhada.

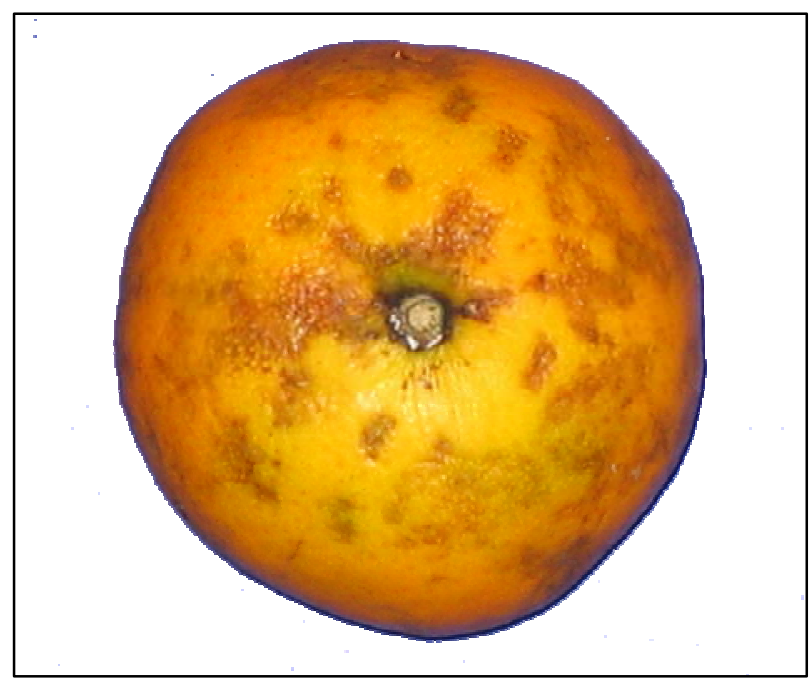

Figura 4 - Aspecto geral de tangor 'Murcott' armazenado por 4 semanas a $1^{\circ} \mathrm{C}$ seguido de 4 dias de comercialização

A maior incidência de danos por frio foi verificada nos frutos do controle e naqueles que foram tratados com imazalil a $25^{\circ} \mathrm{C}$ (Figuras 5 e 6). Já aqueles armazenados a $4^{\circ} \mathrm{C}$ não apresentaram danos por frio até a oitava semana, mesmo após os dias de comercialização simulada. Esse resultado era esperado, uma vez que a temperatura de armazenamento encontra-se dentro da faixa recomendada para o tangor 'Murcott' (Hardenburg et al., 1986; ASHRAE, 1994; Cantwell, 2001). Uma explicação para esse comportamento é que o desenvolvimento de danos por frio depende tanto da temperatura quanto 
do tempo de exposição a ela (Chitarra \& Chitarra, 1990; Schirra et al., 1997a), justificando o não aparecimento de sintomas até a quarta semana de armazenamento nas frutas armazenadas a $1^{\circ} \mathrm{C}$. Nos tratamentos onde foi incluído tratamento térmico (água quente com ou sem fungicida) foi observada uma redução significativa no aparecimento de sintomas de danos por frio, o que também foi verificado por outros autores (McDonald et al., 1991; Martinez-Téllez \& Lafuente, 1997).

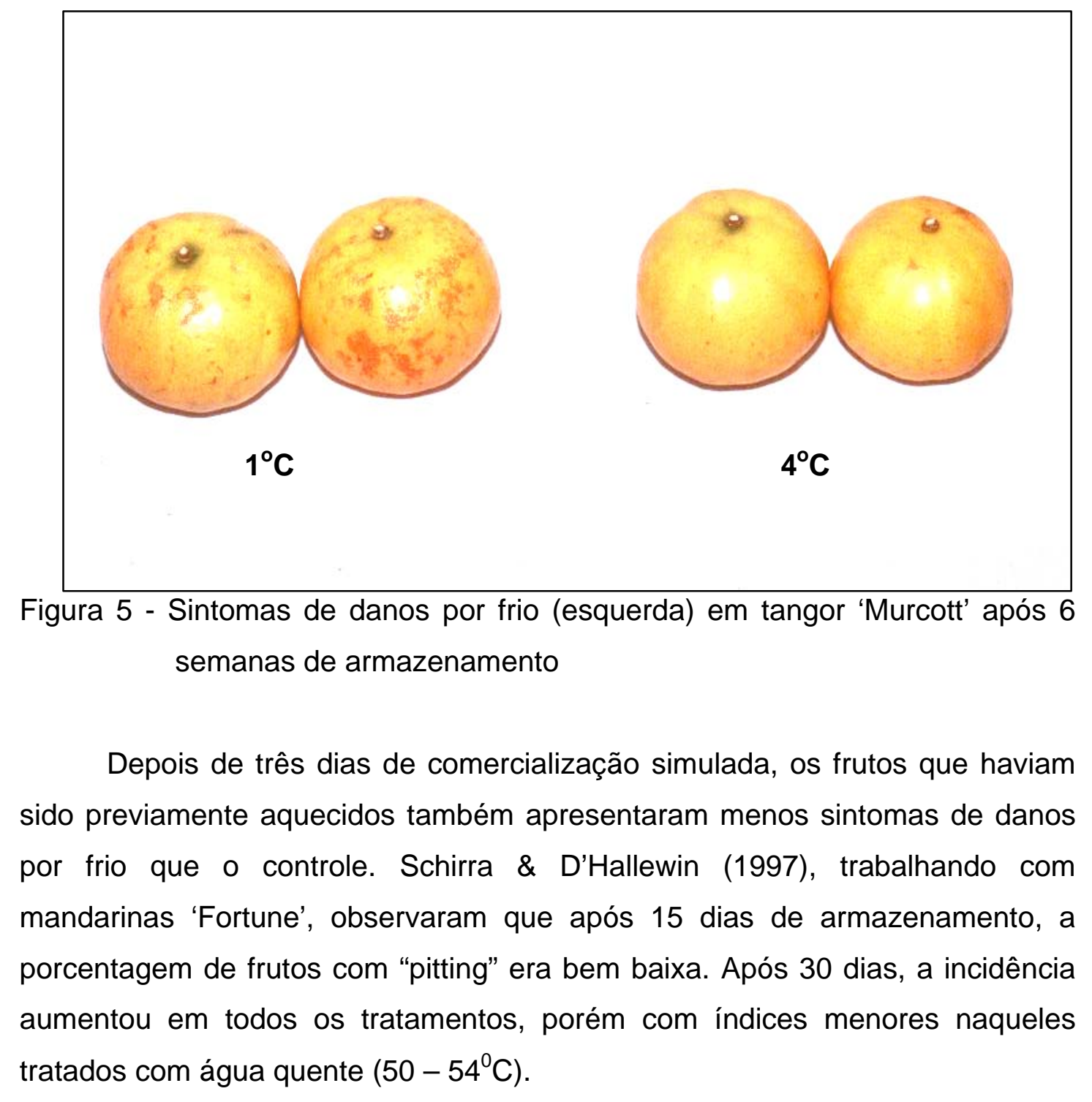




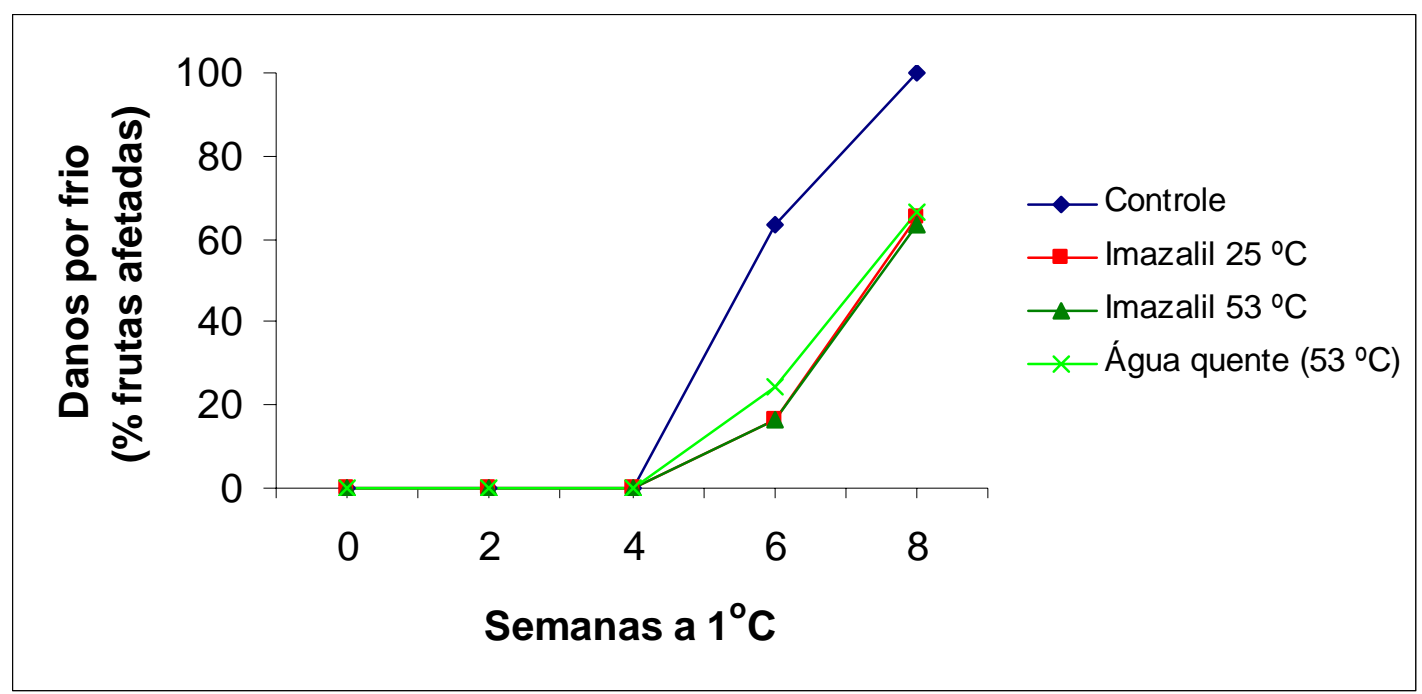

Figura 6 - Danos por frio em tangor 'Murcott' submetidas a diferentes tratamentos e armazenadas a $1^{\circ} \mathrm{C} .1=0 \%$ da superfície afetada; 2 $<5 \%$; $3=5-25 \% ; 4=25-50 \%$ e $5=>50 \%$. As barras verticais indicam o desvio padrão da média

Laranjas 'Valência' (Citrus sinensis L. Osbeck) tratadas com água a $53^{\circ} \mathrm{C}$ por três ou seis minutos apresentaram redução nos sintomas de "chilling", quando comparadas ao controle, após seis meses de armazenamento a $4^{\circ} \mathrm{C}$ (Erkan et al., 2005). Nesse mesmo experimento, foram testados cura a $53^{\circ} \mathrm{C}$ por seis horas e a $48^{\circ} \mathrm{C}$ por doze horas. Os tratamentos realizados por um período maior foram mais eficazes do que aqueles feitos por curto período $\left(53^{\circ} \mathrm{C}\right.$ por 3 ou 6 minutos).

Quanto à incidência de podridões, observou-se, de maneira geral a presença de menos de $5 \%$ de área afetada com podridão nos tratamentos controle após o período de 6 semanas de armazenamento. Os fungos mais comumente observados foram Penicillium spp (Figura 7). Considerou-se, então, como uma incidência baixa e não significativa. Dois fatores podem ter contribuído para isso: um bom controle fitossanitário no pomar, na pré-colheita, o que foi confirmado por informação do produtor, e a própria baixa temperatura 
de armazenamento, que pode ter contribuído para a supressão do desenvolvimento de patógenos. Isso pode se tornar importante, considerando que os tratamentos químicos estão sendo cada vez mais proibidos em póscolheita. A inclusão do tratamento com água quente no experimento objetivou verificar se havia efeito também sobre as podridões. Alguns autores relatam que a água quente, com ou sem fungicida, pode reduzir significativamente a incidência de podridões durante o armazenamento (Schirra \& Mulas, 1993; Rodov et al., 1995 e 2000). Em conseqüência da baixa incidência de fungos, não foi possível observar esse efeito no experimento que realizamos.

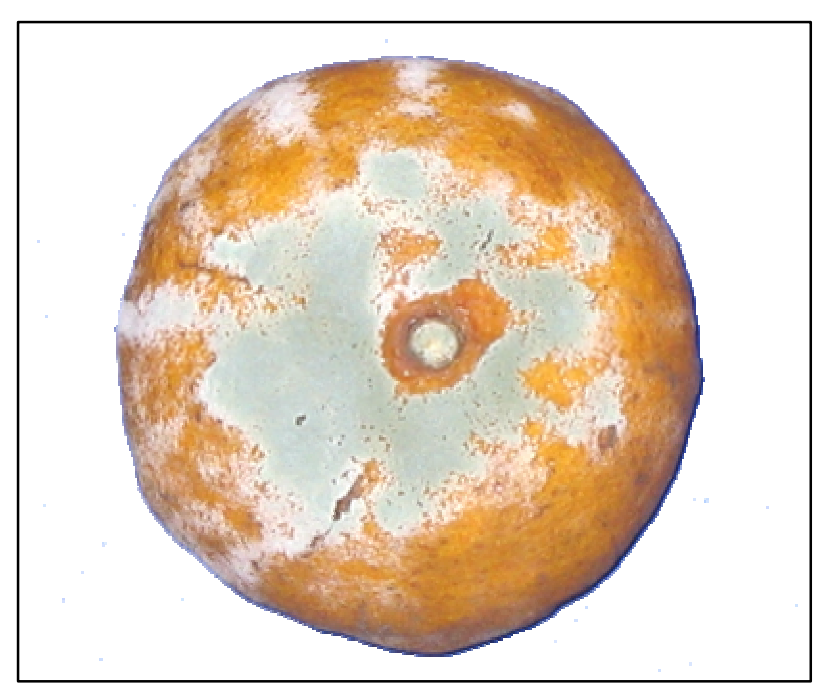

Figura 7 - Aspecto geral de podridão em tangor 'Murcott' armazenado durante 6 semanas seguido de 4 dias de comercialização simulada

Shirra \& D'hallewin (1997) não detectaram o aparecimento de podridões após 15 dias de armazenamento em mandarinas 'Fortune' tratadas a $51-54^{\circ} \mathrm{C}$. No final do armazenamento (após 30 dias) as diferenças causadas pelo ataque de patógenos não foram significativas.

Kumquat responderam favoravelmente ao tratamento térmico a $51-53^{\circ} \mathrm{C}$ por 2 minutos, diminuindo drasticamente as podridões causadas por Penicillium spp (Ben - Yehoshua et al., 2000). 
Na Tabela 1 está resumida a análise de variância para os efeitos dos tratamentos sobre as diversas variáveis analisadas durante o experimento, para as frutas armazenadas a $1^{\circ} \mathrm{C}$. Observou-se que os efeitos significativos mais pronunciados foram, na sua maioria, em função do tempo de armazenamento. Os efeitos dos tratamentos térmicos se refletiram na perda de massa e na maior resistência aos danos por frio.

Tabela 1. Significância do teste $F$ da análise de variância para os efeitos dos diferentes fatores sobre os parâmetros físico-químicos e danos por frio em tangor 'Murcott' armazenadas a $1^{\circ} \mathrm{C}$

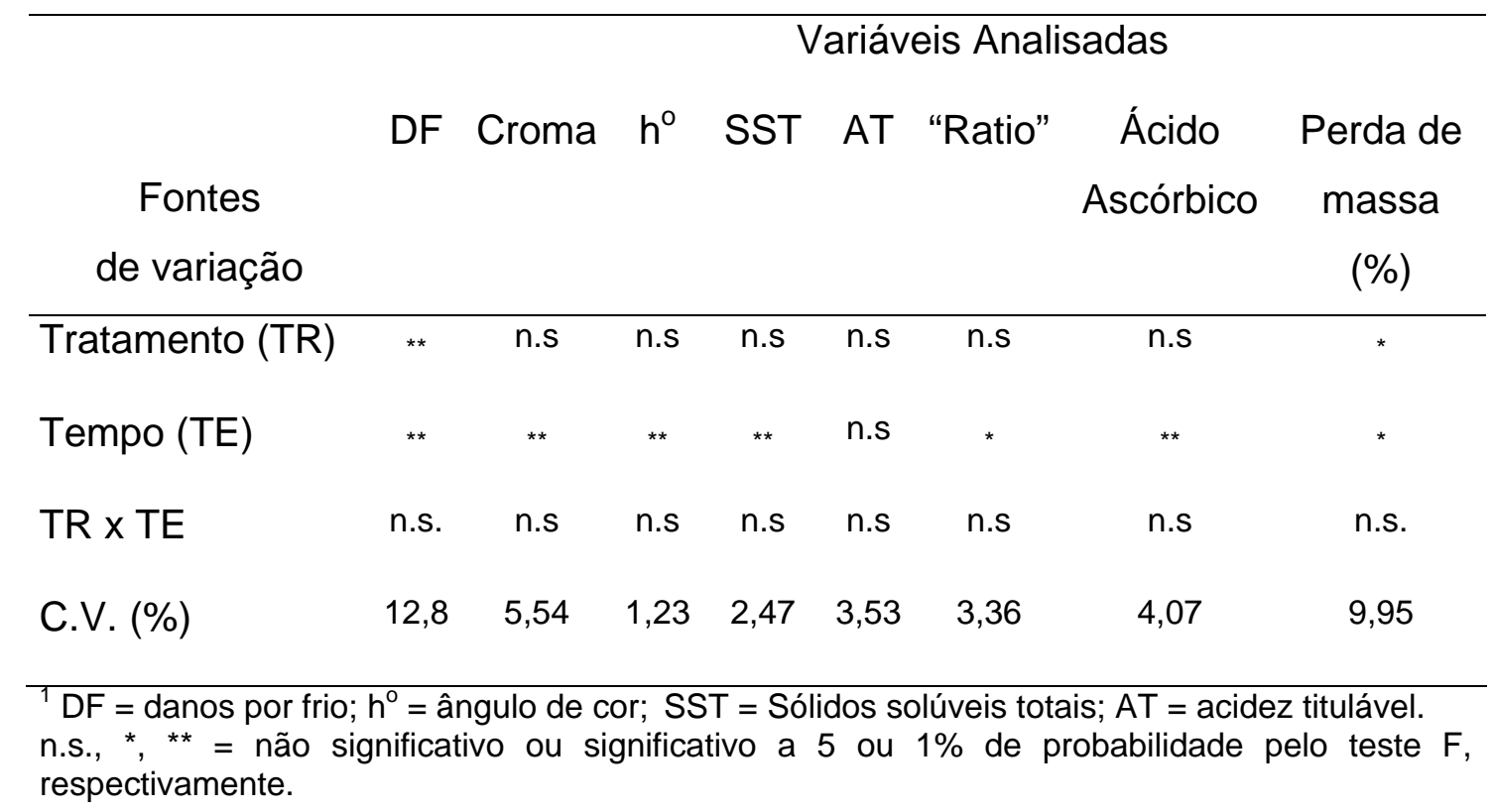

Para a temperatura de $4^{\circ} \mathrm{C}$ o único efeito isolado dos tratamentos refletiuse na perda de massa dos frutos (Tabela 2). As demais variáveis foram mais influenciadas pelo tempo de armazenamento.

Observou-se, de maneira geral, um aumento na perda de massa ao longo do período de armazenamento, tendo sido observada também diferença entre os tratamentos (Figura 8). Os frutos tratados com água quente, com e sem fungicida, foram os que apresentaram maior perda de massa. A perda de 
massa varia em função das taxas de respiração e transpiração, processos estes relacionados com a perda de água do fruto. No caso dos citros, esta perda provém principalmente da casca. A elevada perda de massa nos tratamentos com altas temperaturas era esperada, considerando-se que os tratamentos térmicos elevam o déficit de pressão de vapor (DPV) entre os tecidos internos do fruto e o ambiente, favorecendo um aumento na transpiração (Hardenburg et al., 1986).

Tabela 2. Significância do teste $F$ da análise de variância para os efeitos dos diferentes fatores sobre os parâmetros físico-químicos em tangor 'Murcott' armazenado a $4^{\circ} \mathrm{C}$

Variáveis Analisadas

DF Croma $h^{\circ}$ SST AT "Ratio" Ácido Perda de

Fontes Ascórbico massa

de variação

Tratamento (TR) n.s

n.s

n.s n.s

n.s

n.s

Tempo (TE)

TR $\times$ TE

n.s

n.s

n.s n.s

n.s

n.s

n.s.

C.V. (\%)

$5,75 \quad 3,03 \quad 4,72 \quad 3,35 \quad 3,71$

4,33

10,44

${ }^{1} \mathrm{DF}$ = danos por frio; $\mathrm{h}^{0}$ = ângulo de cor; SST = Sólidos solúveis totais; AT = acidez titulável. n.s., *, ** = não significativo ou significativo a 5 ou $1 \%$ de probabilidade pelo teste $\mathrm{F}$, respectivamente. 
No armazenamento a $4^{\circ} \mathrm{C}$ foram verificadas menores diferenças entre os tratamentos, com uma leve tendência, na segunda semana, dos frutos tratados com água quente a $53^{\circ} \mathrm{C}$ (com ou sem fungicida) apresentarem maior perda de massa. Na sexta e oitava semanas as diferenças tornaram-se menores (Figura 8). Ao final do período de 8 semanas as frutas apresentavam-se com início de murchamento.

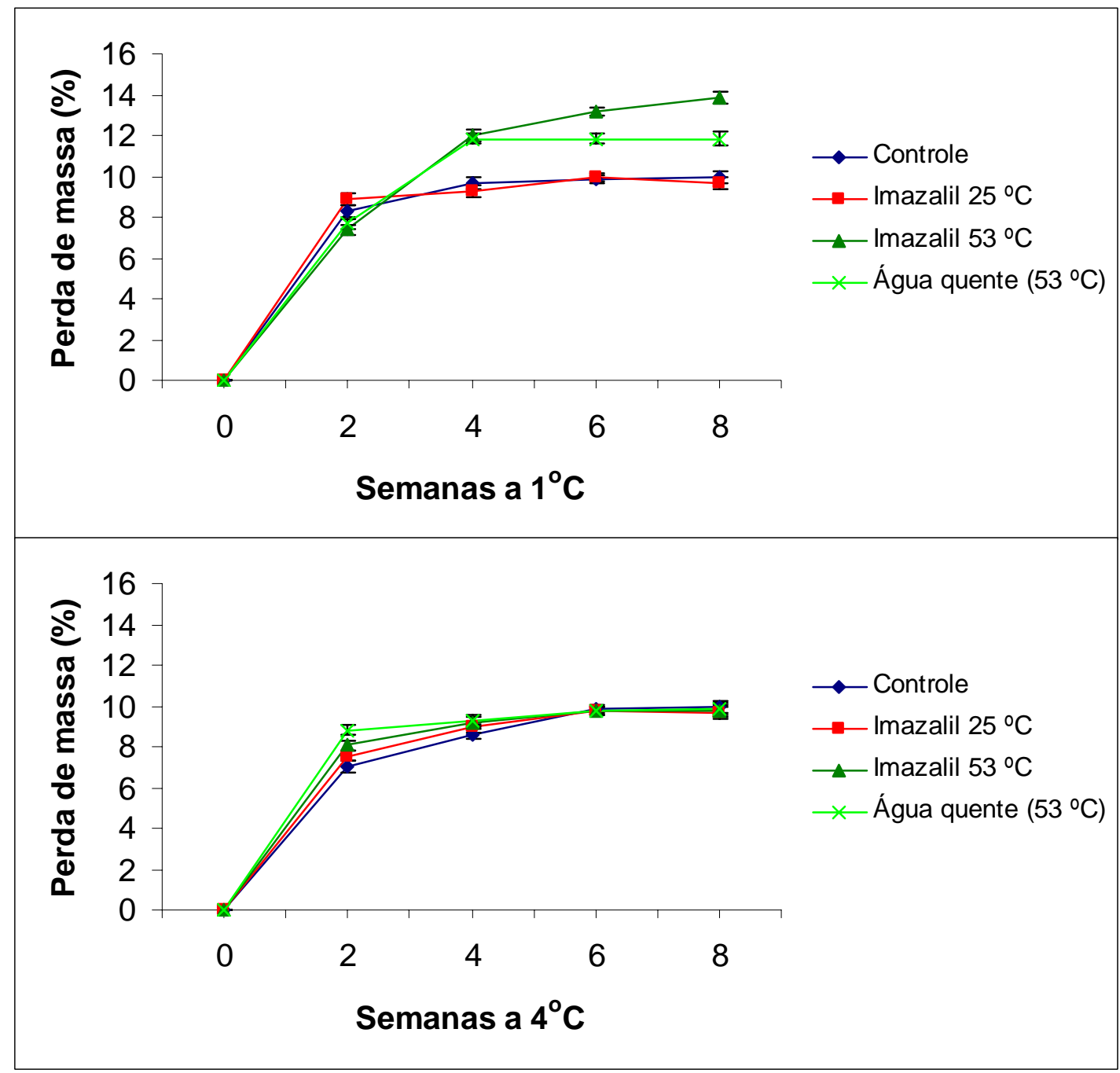

Figura 8 - Perda de massa em tangor 'Murcott' submetido a diferentes tratamentose armazenado a 1 e $4^{\circ} \mathrm{C}$. As barras verticais indicam o desvio padrão da média 
Em laranjas 'Valência' tratadas a $53^{\circ} \mathrm{C}$ por 3 ou 6 minutos, a $53^{\circ} \mathrm{C}$ por 6 horas e a $48^{\circ} \mathrm{C}$ por 12 horas e depois armazenados a $4^{\circ} \mathrm{C}$, houve uma maior perda de massa nos frutos expostos por mais tempo ao calor. Isso era esperado, já que a perda de massa está ligada ao tempo de exposição do produto, além da temperatura. Porém, não houve diferenças significativas entre os tratamentos ao final dos 6 meses de armazenamento e uma semana de comercialização simulada (Erkan et al., 2005).

Porat et al. (2000b) observaram, em estudo com pomelos 'Star Ruby', que frutos previamente estocados a $21^{\circ} \mathrm{C}$ e $16^{\circ} \mathrm{C}$ por 7 dias e "curados" por 3 dias a $36^{\circ} \mathrm{C}$ apresentaram uma crescente perda de massa quando comparados ao controle. Entretanto, o tratamento a $53^{\circ} \mathrm{C}$ por 2 minutos não apresentou perda de massa diferente do controle.

Os valores de ácido ascórbico apresentaram decréscimo acentuado na segunda semana de armazenamento, em ambas as temperaturas (1 e $4^{\circ} \mathrm{C}$ ). Depois da segunda semana, até o final do período, os valores se mantiveram constantes e próximos de 20mg/100mL (Figura 9), sem diferenças significativas entre os tratamentos.

Reduções no teor de ácido ascórbico são esperados após a colheita, já que existe uma relação inversa entre senescência e conteúdo de ácido ascórbico. O ácido ascórbico é um antioxidante natural envolvido em reações que se processam durante a senescência dos frutos, como forma de reparar danos oxidativos nas células. Este decréscimo depende, em grande parte, da temperatura e da duração do armazenamento (Thé, 2001). Possíveis aumentos no teor de ácido ascórbico também podem ocorrer, considerando que sua biossíntese está ligada à degradação de pectinas, que libera precursores do ácido ascórbico (Agius et al., 2003). É provável que a partir da segunda semana de armazenamento tenha ocorrido um balanço entre utilização e biossíntese de ácido ascórbico. 


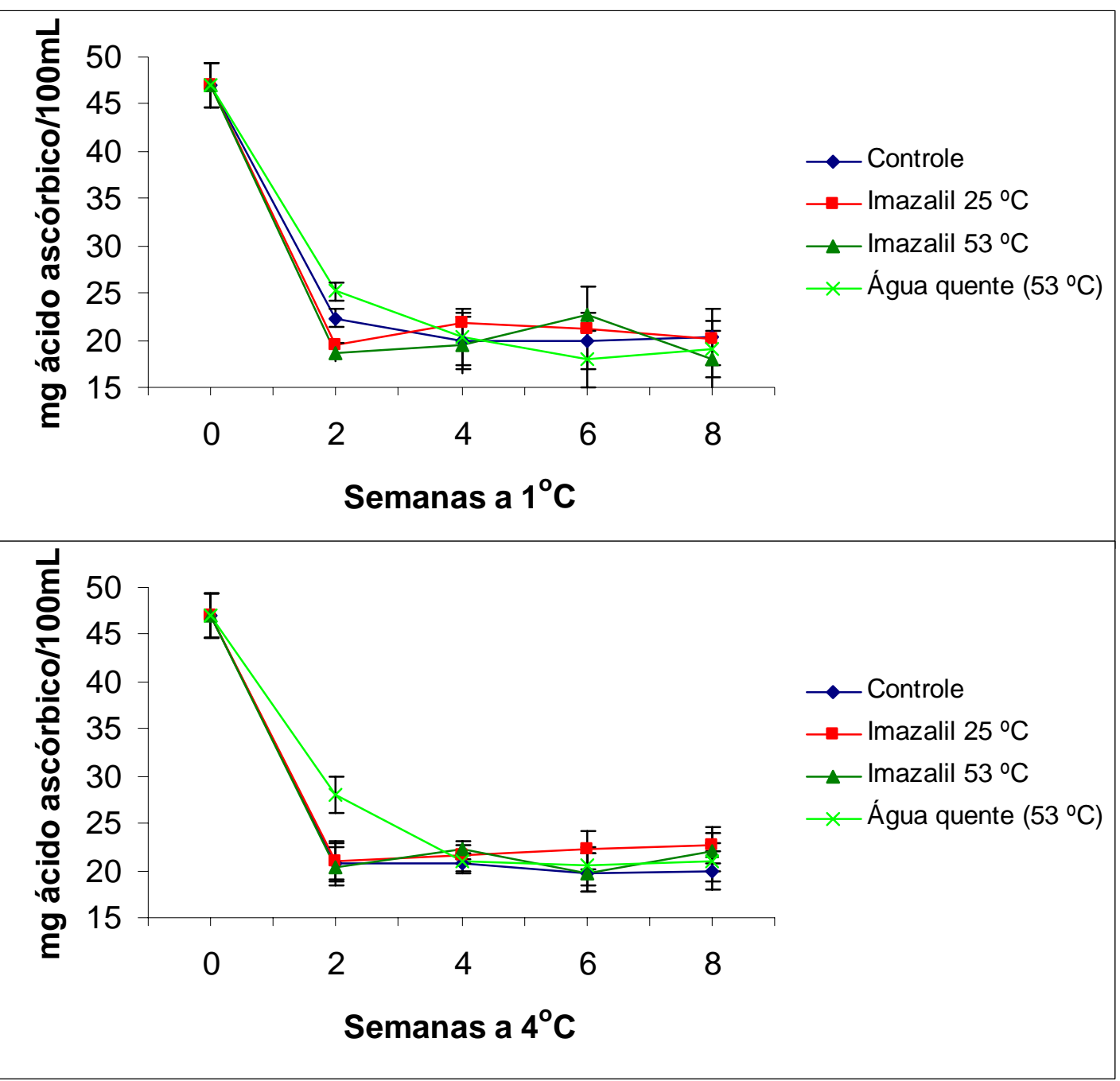

Figura 9 - Teor de ácido ascórbico (mg ácido ascórbico/100mL) em tangores 'Murcott' submetidas a diferentes tratamentos e armazenadas a 1 e $4^{\circ} \mathrm{C}$. As barras verticais indicam o desvio padrão da média

Erkan et al. (2005), estudando laranjas 'Valência', observaram que o teor de ácido ascórbico diminui significativamente durante o armazenamento. Nos frutos tratados com água quente esta diferença se mostrou ainda maior, 
apresentando diferenças entre os diferentes tratamentos térmicos, o que não foi observado no presente trabalho.

De acordo com Gonçalves (1998), o conteúdo de vitamina C natural de muitos frutos depende de vários fatores, incluindo cultivares, estádio de maturação (no caso de frutos climatéricos), condições de cultivo e colheita.

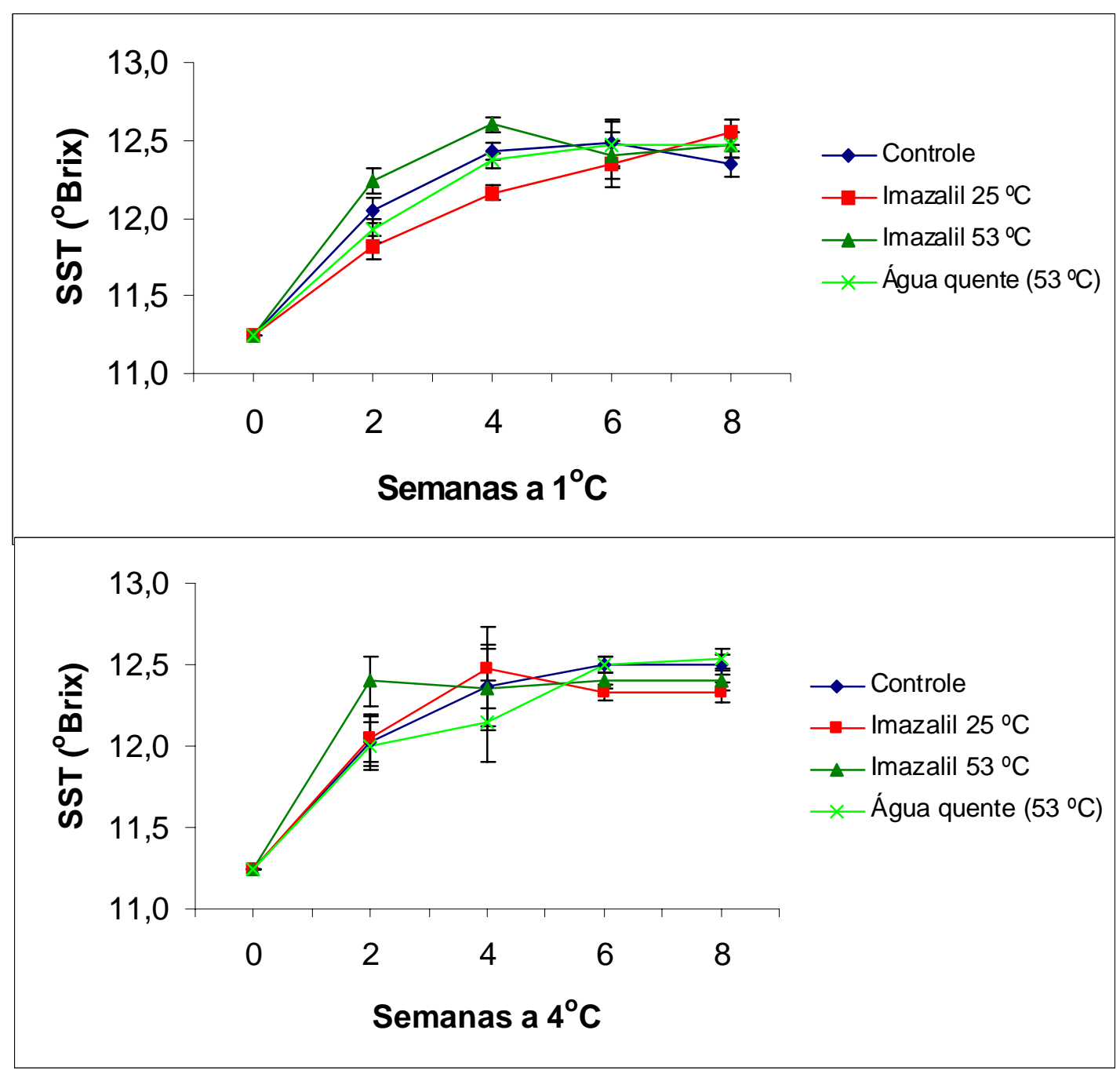

Figura 10 - Teor de sólidos solúveis totais (SST) em tangores 'Murcott' submetidas a diferentes tratamentos e armazenadas a 1 e $4^{\circ} \mathrm{C}$. As barras verticais indicam o desvio padrão da média 
Também observamos que não houve diferença significativa no teor de SST entre os tratamentos durante o período estudado. Entretanto, houve uma elevação nos valores de SST ao longo do experimento (Figura 10).

Os aumentos nos teores de sólidos solúveis são geralmente atribuídos à perda de massa dos frutos que foi crescente no presente trabalho. Embora a perda de massa por transpiração em citros se dê quase que exclusivamente a partir da casca, pode haver também perda de água na forma de vapor a partir do interior das frutas através da columela e inserção do pedúnculo (Ting \& Roussef, 1986).

O teor de sólidos solúveis é um indicativo da quantidade de açúcares existentes no fruto, considerando que outros compostos, embora em reduzidas proporções, também façam parte, como por exemplo, ácidos, vitaminas, aminoácidos e algumas pectinas. O teor de SST dá uma idéia de doçura do fruto durante a maturação e é um importante atributo na determinação de seu sabor (Kluge et al., 2002).

Com a maturação, ocorre a síntese dos sólidos solúveis ou a degradação de polissacarídeos, fazendo com que seu valor aumente até certo ponto, a partir do qual começam a ser utilizados na manutenção da atividade metabólica dos frutos (Bron et al., 2002), enquanto que o pH aumenta (Holland, 1993).e o teor de acidez diminui (Erkan et al., 2005).

Em todos os tratamentos, os teores de acidez titulável (AT) variaram pouco durante o armazenamento (Figura 11) mostrando que, em tangores, esta variável não se modifica drasticamente durante a senescência. Os valores de acidez titulável oscilaram entre 1 e 1,2\% de ácido cítrico, não tendo havido diferenças entre os tratamentos. Para a maioria dos frutos, a redução na acidez é um evento normal e a velocidade com que ela ocorre é diretamente proporcional à temperatura que afeta a produção de etileno e a atividade respiratória. Os ácidos predominantes encontrados nos frutos são o málico, o cítrico, o oxálico, o tartárico, o acético, dentre outros (Wills et al., 1998). No tangor 'Murcott' o ácido mais importante é o cítrico. 


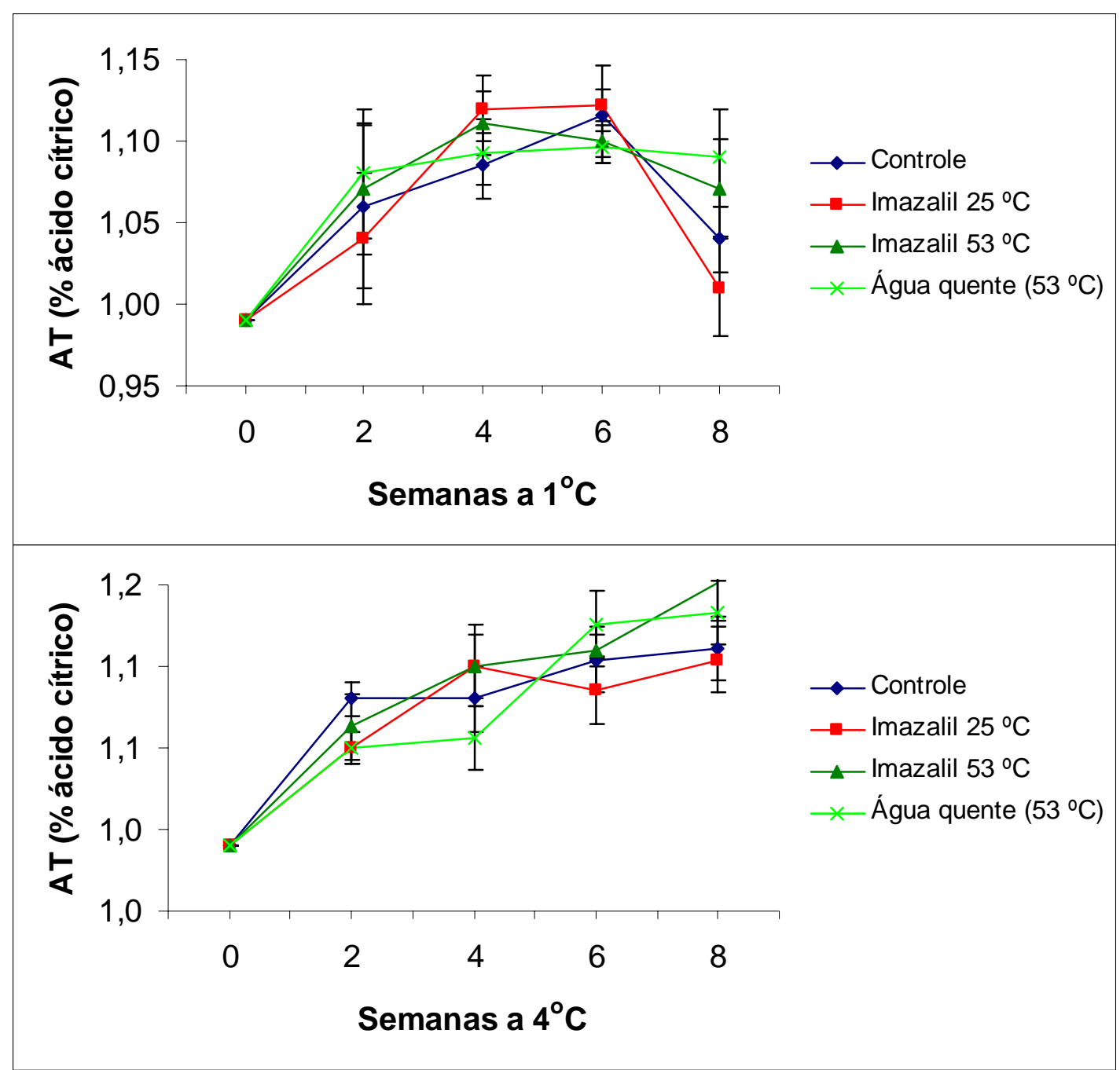

Figura 11 - Acidez total (AT) em tangores 'Murcott' submetidas a diferentes tratamentos e armazenadas a 1 e $4^{\circ} \mathrm{C}$. As barras verticais indicam o desvio padrão da média

Porat et al. (2000b), estudando pomelos 'Star Ruby', observaram que os tratamentos não provocaram mudanças significativas na acidez encontrada no suco de frutas tratadas, quando comparadas com aquela do controle. 
Conhecendo-se os valores dos sólidos solúveis totais e da acidez titulável, pode-se obter a relação entre esses dois parâmetros. Esta relação é utilizada em muitos frutos para se avaliar o grau de maturação, já que esse quociente determina o "flavour" do produto. Poucas alterações significativas no ratio foram observadas no experimento, tendo os valores oscilado entre 10 e 12 (Figura 12), em função dos valores de SST e AT obtidos.



Figura 12 - Ratio (SST/AT) em tangor 'Murcott' submetidas a diferentes tratamentos e armazenadas a 1 e $4^{\circ} \mathrm{C}$. As barras verticais indicam o desvio padrão da média 
Uma leve ascensão nesta variável, ao final do armazenamento a $1^{\circ} \mathrm{C}$, deveu-se à pequena queda na AT e pequeno aumento no SST, não havendo diferenças significativas entre os tratamentos.

Em tangor 'Murcott', a mudança que ocorre na cor da epiderme é um dos principais fatores utilizados pelo consumidor para avaliar a qualidade do fruto. Decorre daí o interesse em acompanhar a evolução de grandezas como o ângulo de cor e a intensidade (croma) que quantificam esse aspecto. No presente experimento, houve desenvolvimento de coloração característica da fruta ao longo do período estudado em todos os tratamentos, e em ambas temperaturas de armazenamento (Figuras 13 e 14). Assim, os valores de ângulo de cor $\left(\mathrm{h}^{\circ}\right)$ tiveram uma redução ao longo do armazenamento, que ficou mais evidente nas frutas armazenadas a $4^{\circ} \mathrm{C}$, que apresentavam-se um pouco mais alaranjadas que aquelas armazenadas a $1^{\circ} \mathrm{C}$. No caso do tangor 'Murcott', valores próximos a $90^{\circ}$ representam fruta amarela e valores próximos de $120^{\circ}$ estão associados a frutas verdes. À medida que o ângulo de cor vai decrescendo abaixo de $90^{\circ}$ indica que a fruta vai passando de amarelo para laranja. De maneira geral, para frutas maduras, o ângulo de cor desta cultivar localiza-se entre 75 e $90^{\circ}$ enquanto que para a intensidade de cor (croma) estes valores oscilam entre 40 e 60 (McGuire, 1992). No presente experimento, o croma inicial era de aproximadamente 56 e o valor máximo atingido, ao longo do armazenamento, foi de 60 (Figura 14).

Porat et al. (2000b), estudando pomelos 'Star Ruby', verificou que frutos tratados e não tratados apresentaram a mesma evolução da cor durante o período de armazenamento, constatando que os tratamentos térmicos não provocaram mudanças na cor da casca. O mesmo foi verificado por Schirra \& D'Hallewin (1997) que não constataram diferenças na cor da casca de mandarinas 'Fortune' tratadas termicamente ou não. 




Figura 13 - Ângulo de cor em tangor 'Murcott' submetido a diferentes tratamentos e armazenado a 1 e $4^{\circ} \mathrm{C}$. As barras verticais indicam o desvio padrão da média 


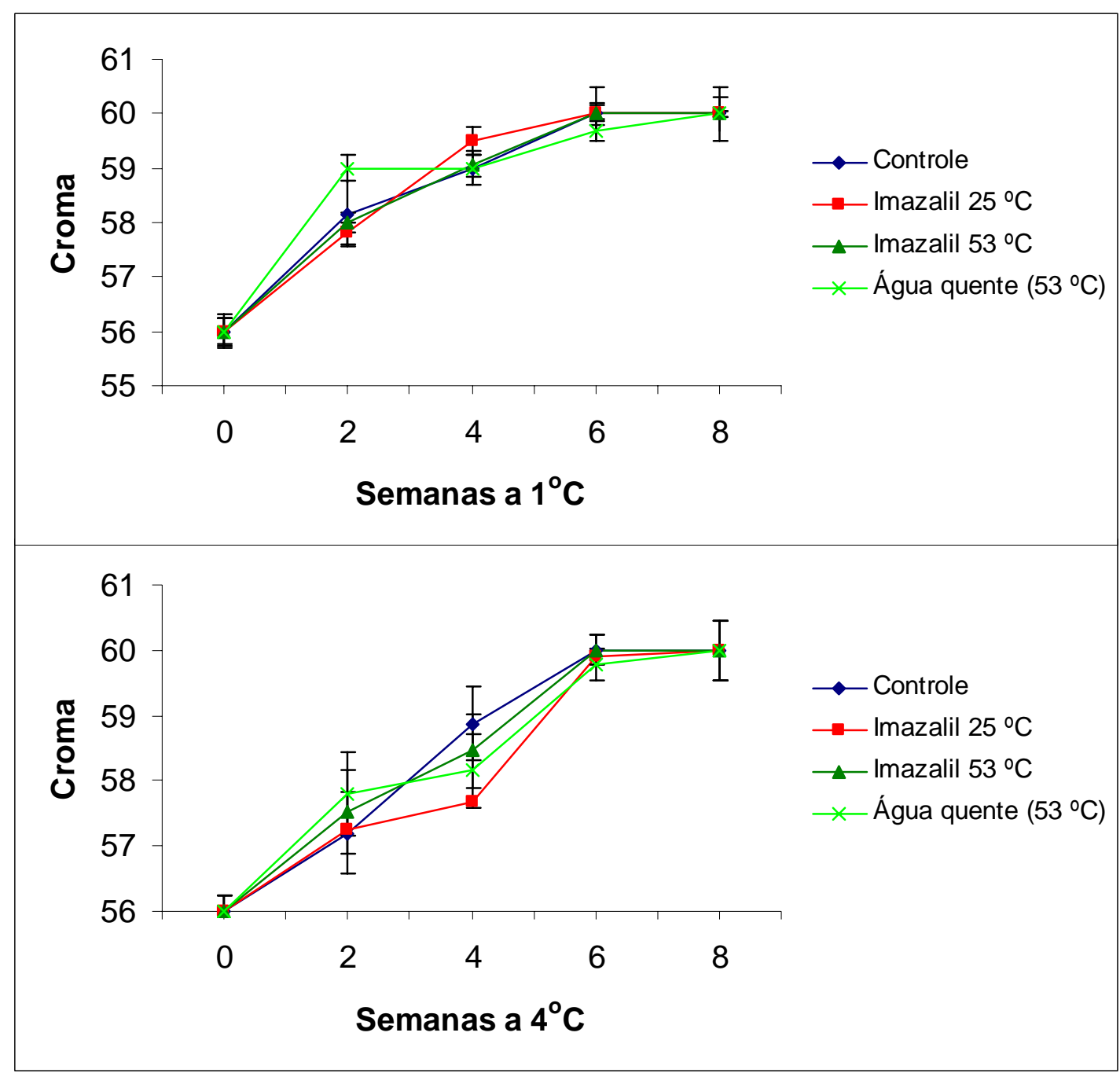

Figura 14 - Croma em tangor 'Murcote' submetidas a diferentes tratamentos e armazenado a 1 e $4^{\circ} \mathrm{C}$. As barras verticais indicam o desvio padrão da média

A mudança na coloração dos frutos está ligada à intensidade do metabolismo, ou seja, quanto maior for o metabolismo maior é a degradação da clorofila e a síntese de carotenóides (Chitarra \& Chitarra, 1990). 
Nas Tabelas 3 e 4 estão apresentados os quadros de análise de variação para os parâmetros de análise sensorial.

Tabela 3. Significância do teste $F$ da análise de variância para os efeitos dos diferentes fatores sobre os parâmetros de avaliação sensorial em tangor 'Murcott' armazenadas a $1^{\circ} \mathrm{C}$

Fontes de variação Odor estranho Sabor estranho Qualidade global

\begin{tabular}{lccc}
\hline Tratamento (TR) & n.s & n.s & $* *$ \\
Tempo (TE) & $* \star$ & $* *$ & $* *$ \\
TR $\times$ TE & n.s. & n.s & $*$ \\
C.V. $(\%)$ & 8,49 & 8,56 & 9,47
\end{tabular}

n.S., ${ }^{*},{ }^{* *}=$ não significativo ou significativo a 5 ou $1 \%$ de probabilidade pelo teste $F$, respectivamente.

Tabela 4. Significância do teste $F$ da análise de variância para os efeitos dos diferentes fatores sobre os parâmetros de avaliação sensorial em tangor 'Murcott' armazenadas a $4^{\circ} \mathrm{C}$

\begin{tabular}{lccc}
\hline Fontes de variação & Odor estranho & Sabor estranho & Qualidade global \\
\hline Tratamento (TR) & n.s & n.s & $*$ \\
Tempo (TE) & $*$ & $*$ & $*$ \\
TR x TE & n.s. & n.s & n.s. \\
C.V. (\%) & 9,57 & 16,40 & 10,97 \\
$\begin{array}{l}\text { n.S., }{ }^{*},{ }^{*} \text {, não significativo ou significativo a } 5 \text { ou } 1 \% \text { de probabilidade pelo } \\
\text { teste F, respectivamente. }\end{array}$
\end{tabular}


A análise dessas tabelas permite concluir que não houve efeito dos tratamentos térmicos sobre o odor e sabor estranho, mas houve efeito significativo para os efeitos isolados dos tratamentos e interação para a variável qualidade global. Isto ocorreu em função desta última variável englobar tanto a presença de odor e sabor estranhos quanto a presença de outros atributos que depreciam a qualidade, tais como murchamento visível, presença de danos por frio e outras imperfeições.

Erkan et al. (2005), trabalhando com laranjas 'Valência' tratadas com água quente a $53^{\circ} \mathrm{C} / 3$ ou 6 minutos, $48^{\circ} \mathrm{C} / 12$ minutos e cura $53^{\circ} \mathrm{C} / 1$ ou 6 horas ou 12 horas, verificaram aparência externa e qualidade nutricional satisfatórias após 2 meses de estocagem. Ao final do armazenamento (6 meses), os frutos tiveram um pequeno declínio na qualidade, porém ainda estando aptos ao consumo.

No presente estudo não houve efeito dos tratamentos térmicos, mas o prolongamento do período de armazenamento contribuiu para o aparecimento de leve à moderada presença de odor estranho (Figura 15). Este comportamento era, de certa forma, esperado, considerando que a fruta após a colheita continua o seu processo de senescência e vários eventos deste processo, como degradação e aumento da permeabilidade da membrana e outras disfunções celulares podem levar à formação de compostos que geram odores estranhos, como excesso de álcool e acetaldeído (Ting \& Rouseff, 1986).

Uma ligeira alteração no sabor foi observada (Figura 16), também provavelmente associada à senescência do fruto.

Quanto à qualidade global foram atribuídas notas em função da presença de fatores que depreciam a qualidade da fruta como: odor e sabor estranhos, perda de brilho, murchamento, amassamento, podridões e sobrematuração. De uma maneira geral observou-se um decréscimo na qualidade global (Figura 17), em parte em função da presença de ligeiro a moderada presença de odor estranho e ligeira presença de sabor estranho e também em função da perda 
de brilho, início de murchamento perceptível dos frutos e presença de danos por frio.

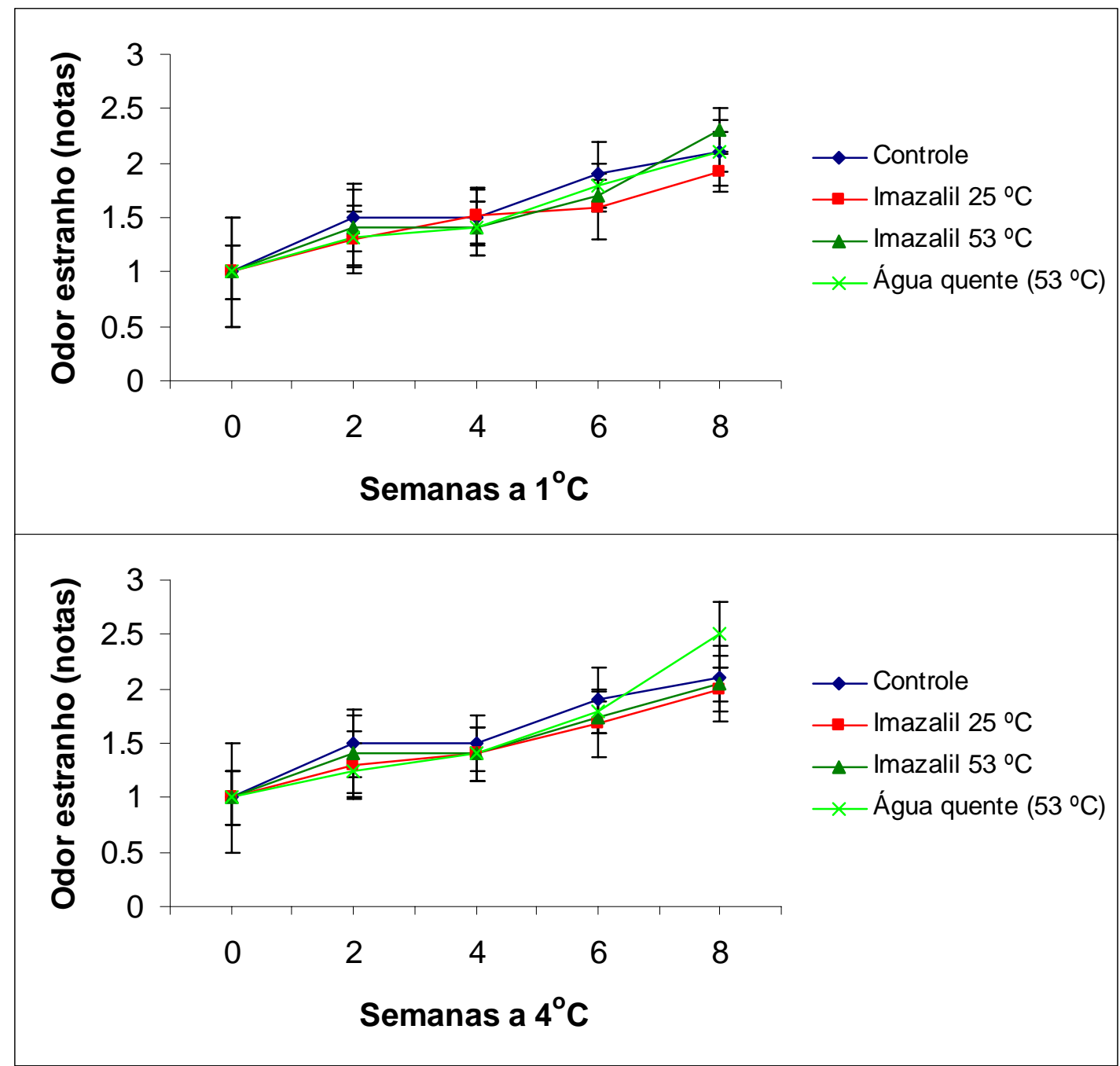

Figura 15 - Avaliação de odor estranho em tangor 'Murcott' submetido a diferentes tratamentos e armazenado a 1 e $4^{\circ} \mathrm{C}$. As barras verticais indicam o desvio padrão da média. Notas de 1 a 5, onde 1 = isento; 2 = ligeiro; 3 = moderado; 4 = intenso e 5 = muito intenso 


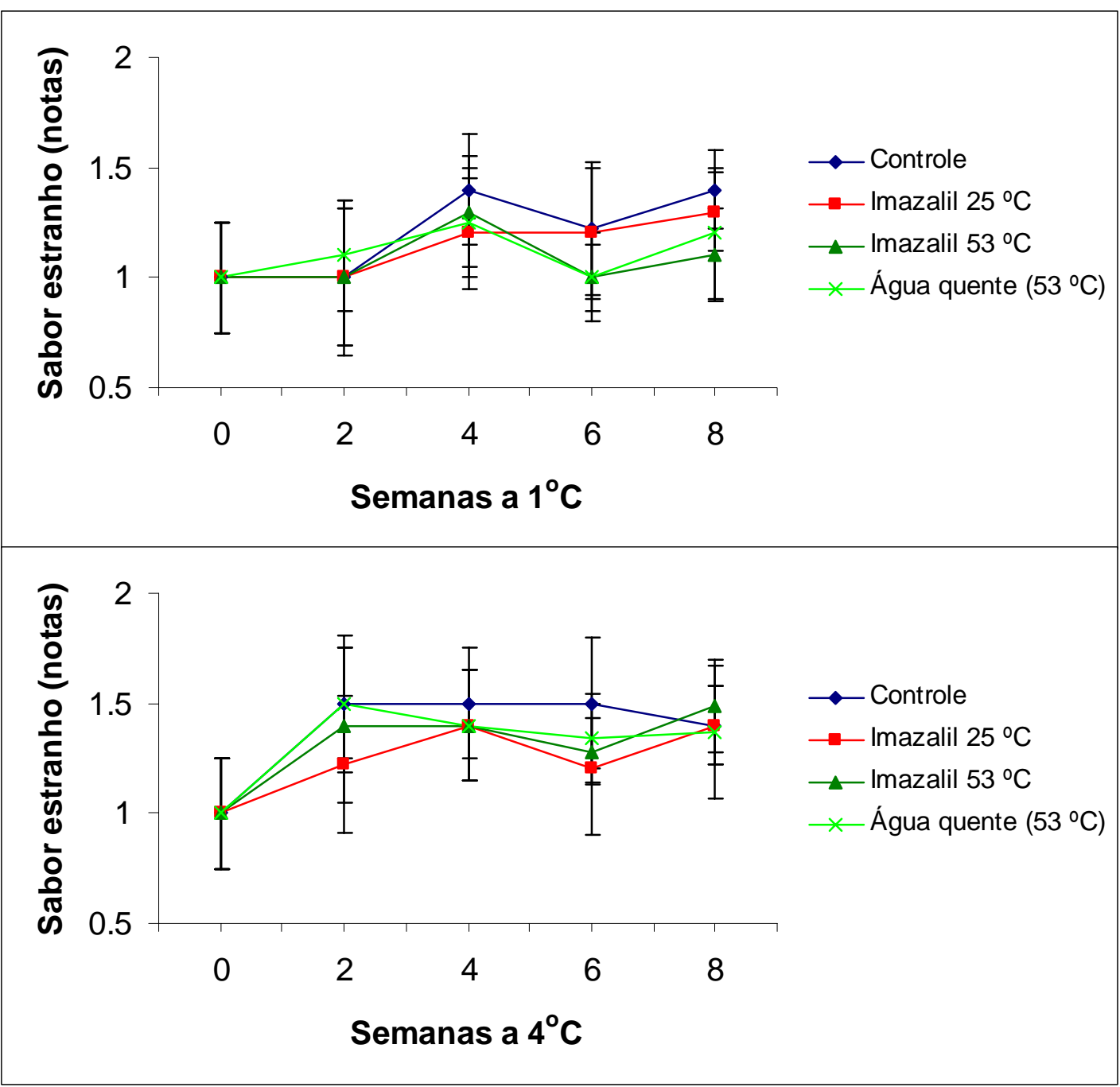

Figura 16 - Avaliação de sabor estranho em tangor 'Murcott' submetido a diferentes tratamentos e armazenado a 1 e $4^{\circ} \mathrm{C}$. As barras verticais indicam o desvio padrão da média. Notas de 1 a 5, onde $1=$ isento; 2 = ligeiro; $3=$ moderado; $4=$ intenso e $5=$ muito intenso 


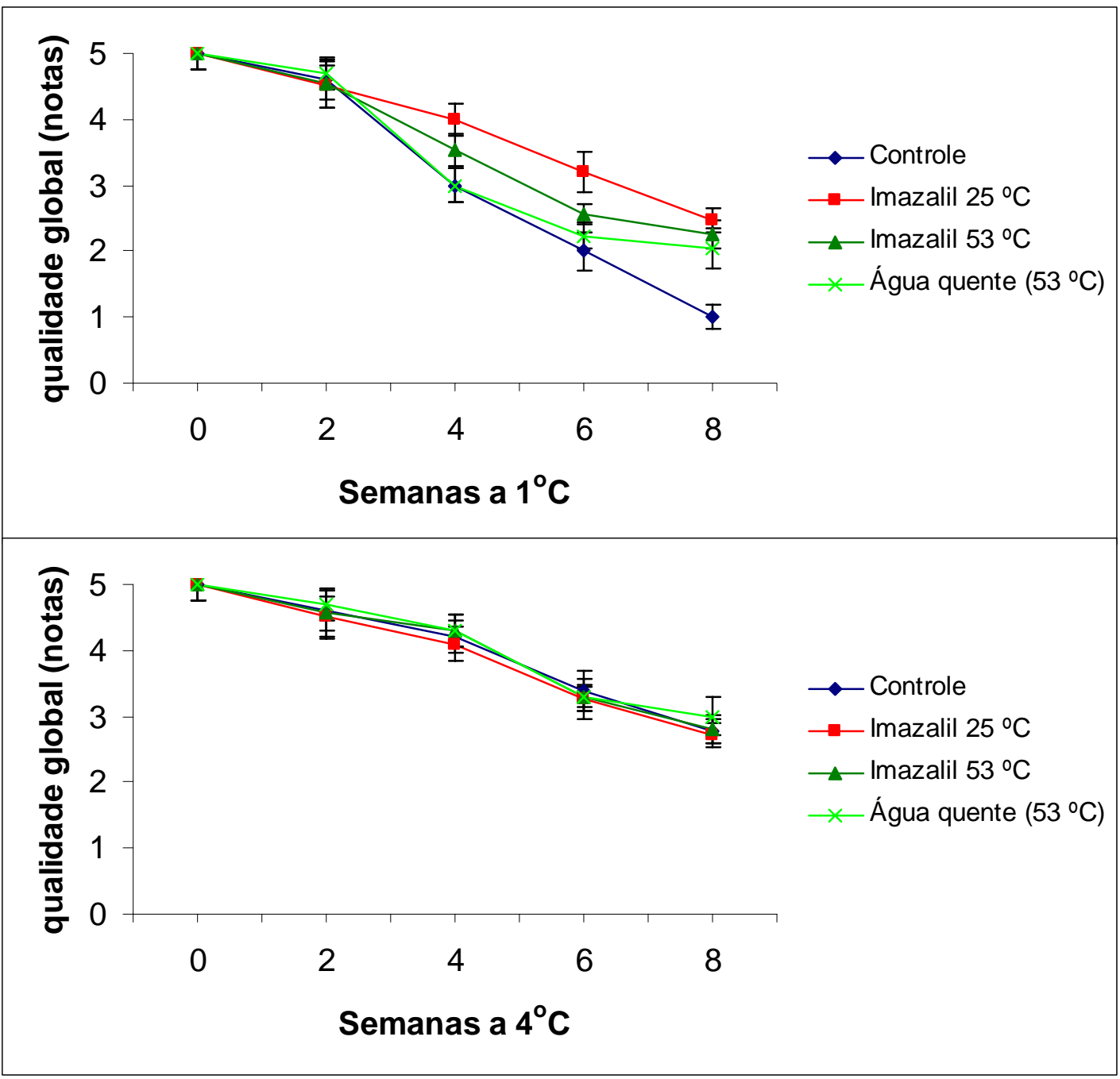

Figura 17 - Avaliação da qualidade global em tangor 'Murcott' submetido a diferentes tratamentos e armazenado a 1 e $4^{\circ} \mathrm{C}$. As barras verticais indicam o desvio padrão da média. Notas de 1 a 5, onde 1 = péssima; 2 = ruim; 3 = razoável; 4 = boa e 5 = ótima

As frutas do controle, armazenadas a $1^{\circ} \mathrm{C}$, apresentaram a maior queda na qualidade global (Figura 17), pois tiveram um alto índice de danos por frio. Ao final de 8 semanas de armazenamento, as frutas apresentaram péssima qualidade, não estando mais aptas para o consumo (Figura 18). Os demais 
tratamentos armazenados a $1^{\circ} \mathrm{C}$ tiveram queda na qualidade, porém menos acentuada, tendo atingido qualidade razoável ao final de 8 semanas, encontrando-se a fruta ainda comercializável. Nas frutas armazenadas à temperatura de $4^{\circ} \mathrm{C}$ também houve queda na qualidade, mas não houve efeito dos tratamentos quando comparados ao controle. Ao final de 8 semanas de armazenamento as frutas encontravam-se com qualidade razoável. Os tratamentos térmicos embora tenham reduzido os danos por frio, aumentam a perda de massa.

A percepção e a aceitabilidade são fatores importantes na avaliação da qualidade dos frutos e vegetais oferecidos no mercado. Embora a maioria dos consumidores mencione o sabor como principal componente na qualidade dos frutos, é na aparência (murchamento, manchas de danos por frio, amassamento e podridões) que se baseiam na hora de escolher frutas e vegetais para saber se encontra-se em estádio avançado de maturação. 
$\begin{array}{llll}\text { A } & \text { B } & \text { C } & \text { D }\end{array}$

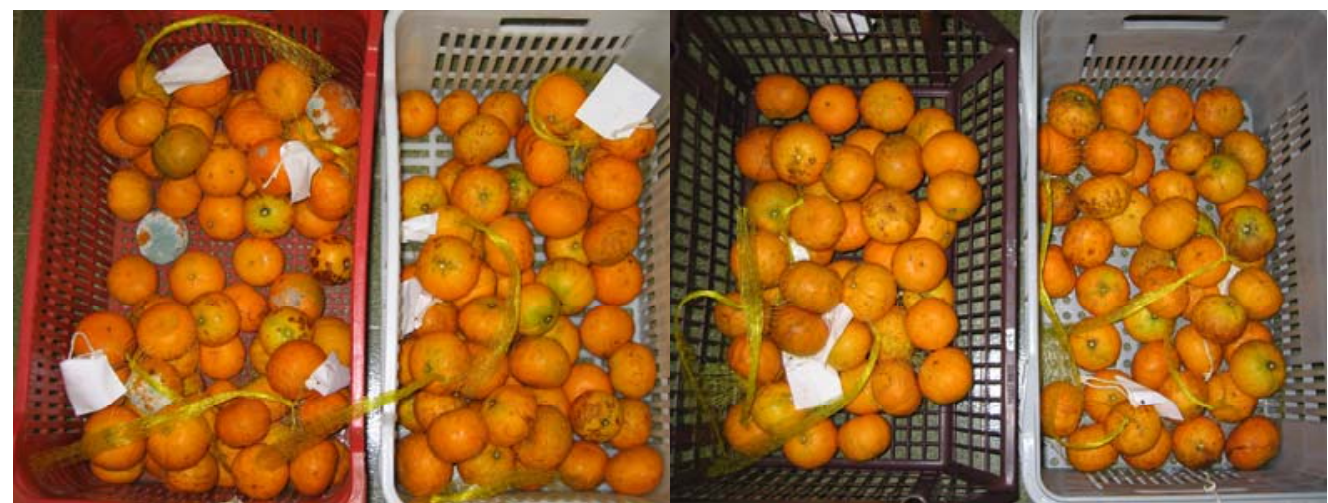

$\mathbf{E}$

F $\quad$ G

H

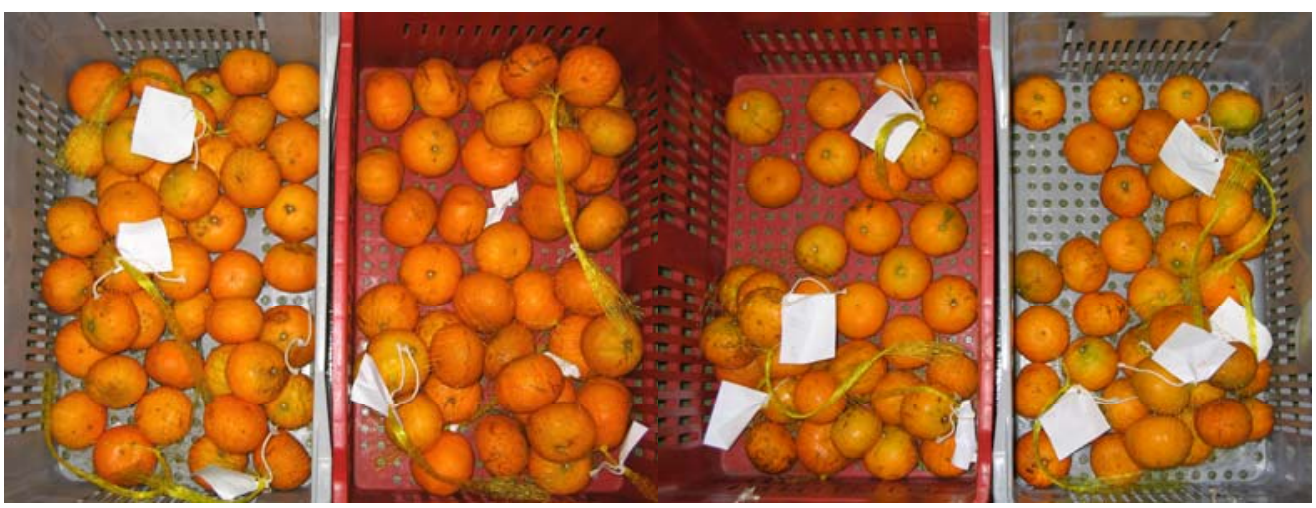

Figura 18 - Aspecto geral de tangores 'Murcott', após 2 meses de armazenamento. A(B) Controle (frutas sem fungicida, apenas imersas em água a $25^{\circ} \mathrm{C}$ durante dois minutos) armazenadas a $1^{\circ} \mathrm{C}\left(4^{\circ} \mathrm{C}\right) ; \mathrm{C}(\mathrm{D})$ Frutas imersas em imazalil $50\left(\mathrm{mg} \mathrm{L}^{-1}\right)$ a $25^{\circ} \mathrm{C}$ por dois minutos e armazenadas a $1^{\circ} \mathrm{C}\left(4^{\circ} \mathrm{C}\right)$; $\mathrm{E}(\mathrm{F})$ Frutas imersas em imazalil $50\left(\mathrm{mg} \mathrm{L}^{-1}\right)$ a $53^{\circ} \mathrm{C}$ por dois minutos, armazenadas a $1^{\circ} \mathrm{C}\left(4^{\circ} \mathrm{C}\right) ; \mathrm{G}(\mathrm{H})$ Frutas imersas apenas em água quente a $53^{\circ} \mathrm{C}$ por dois minutos e armazenadas a $1^{\circ} \mathrm{C}\left(4^{\circ} \mathrm{C}\right)$ 


\section{CONCLUSÕES}

* O armazenamento refrigerado a $4^{\circ} \mathrm{C}$ de frutos de todos os 3 tratamentos, não apresentaram sintomas de danos por frio Os frutos armazenados a $1^{\circ} \mathrm{C}$, por outro lado, sofreram danos por frio a partir da sexta semana de armazenamento. Portanto, tangores 'Murcott"devem ser armazenados a $4^{\circ} \mathrm{C}$.

* Os tratamentos com água quente, associados ou não ao fungicida, podem incrementar a tolerância do fruto às baixas temperaturas e possibilitar dessa forma o armazenamento por um período de tempo mais longo. Porém, além de conhecer os efeitos dos tratamentos térmicos no controle dos danos por frio, é necessário saber a viabilidade prática e econômica da técnica que, depois de estabelecida, pode tornar o tratamento aplicável em nível comercial.

* Esses tratamentos não afetam significativamente as características físicoquímicas dos frutos de tangor 'Murcott', excetuando-se a elevação na perda de massa daqueles que sofreram condicionamento térmico. Mesmo com essa desvantagem, esse atributo só é importante quando esses frutos são destinados à indústria de suco. Para o consumo in natura atributos como cor e turgescência tornam-se relevantes.

* O condicionamento térmico foi efetivo no prolongamento do tempo de armazenamento de tangor 'Murcott', mantendo os frutos ainda aptos ao consumo após 8 semanas de armazenamento a $1^{\circ} \mathrm{C}$. 


\section{REFERÊNCIAS BIBLIOGRÁFICAS}

AGIUS, F.; GONZÁLEZ-LAMOTHE, R.; CABALLERO, J.L.; MUÑOZ-BLANCO, J.; BOTELLA, M.A.; VALPUESTA, V. Engineering increased vitamin C levels in plants by overexpression of a D-galacturonic acid reductase. Nature Biotechnology, v.21, n.2, p.177-181, 2003.

AMARO, A.A.; CASER, D.V. Diversidade do mercado de tangerinas. Informações Econômicas, v.33, n.12, p.51-67, dez.2003.

ARRAS, G.; USAI, M. Response of 'Murcott' mandarins to storage temperature. Advances in Horticultural Science, v.5, p.99-103, 1991.

ARTÉS,F. Inovacciones em los tratamentos físicos para preservar la calidad de productos hortofrutícolas am la postrecolecion. I. Pretratamientos térmicos. Revista Española de Ciência y Tecnologia de Alimentos, v.35, n.1, p.4564, 1995.

ARTÉS, F., ESCRICHER, A.J. Intermittent warming reduces chilling injury and decay of tomato fruit. Journal of Food Science, v.59, p.1053-1056, 1994

ASHRAE. Handbook of refrigeration. Atlanta: American Society of Heating, Refrigeration and Air-Conditioning Engineers, 1994. s.p.d. 
BEN-YEHOSHUA, S.; SHAPIRO, B.; MORAN, R. Individual seal-packaging enables the use of curing at high temperatures to reduce decay and heal injury of citrus fruits. HortScience, v.22, p.777-783, 1987.

BEN-YEHOSHUA, S., PERETZ, J.; RODOV, V.; NAFUSSI, B. Postharvest application of hot water in citrus fruits: the road from the laboratory to the packing house. Acta Horticulturae, v.518, p.19-28, 2000.

BRON, I.U.; JACOMINO, A.P.; APEZZATO-DA-GLÓRIA, B. Alterações anatômicas e físico-químicas associadas ao armazenamento refrigerado de pêssegos 'Aurora-1' e 'Dourado-2'. Pesquisa Agropecuária Brasileira, v.37, n.10, p.1349-1358, 2002.

CAMARGO, A.M.M.P.C.; CASER, D.V.; FRANCISCO, V.L.F.S.; GHOBRIL, C.N. Previsões e estimativas das safras agrícolas do Estado de São Paulo, ano agrícola 2001/02, novembro 2001. Informações Econômicas, v.32, n.2, p.106, 2002.

CANTWELL, M.T. Properties and recommended conditions for long-term storage of fresh fruits and vegetables. http://www.postharvest.ucdavis.edu. (11 jan. 2001).

CARVALHO, C.R.L.; MANTOVANI, D.M.B.; CARVALHO, P.R.N.; MORAES, R.M.M. Análises químicas de alimentos. Campinas: ITAL, 1990. 121p. (Manual Técnico)

CHAN, H.T.; FORBUS, W.B. Delayed light emission as a biochemical indicator of papaya heat treatment. Journal of Food Science, v.53, p.1490-1492, 1988. 
CHITARRA, M.I.; CHITARRA, A.B. Pós-colheita de frutos e hortaliças: fisiologia e manuseio. Lavras: ESAL/FAEPE, 1990. 320p.

COHEN, E. The use of temperature for postharvest decay control in citrus fruit. In: Biological control of postharvest diseases of fruits and vegetables, Shepherdstow, 1990. Proceedings. Shepherdstow,1990. p.256-267.

COHEN, E.; LURIE, S.; YAVIN, S. Prevention of red blotch in the degreened lemon fruit. HortScience, v.23, p.864-865, 1988.

CORTEZ, L.A.B.; CASTRO, L.R.; VIGNEAUT, C. Resfriamento rápido a ar: métodos da câmara frigorífica e do ar forçado. In: CORTEZ, L.A.B.; HONÓRIO, S.; MORETTI, C.L. Resfriamento de frutas e hortaliças. Brasília: Embrapa Informação Tecnológica, 2002. cap. 11, p.231-272.

DAVIES, F.S.; ALBRIGO, L.G. Crop production in horticulture 2. Citrus. London: CAB INTERNATIONAL, 1994. 254p.

DEL RIO, M.A.; CUQUERELLA, J.; RAGONE, M.L. Effects of postharvest curing at high temperature on decay and quality of 'Marsh' grapefruits and navel orange. In: TRIBULATO, E.; GENTILE, E.; REFORGIATO, G. (Ed). Proceedings of the International Society of Citriculture, v.3, p.10811083, 1992.

ERKAN, M.; PEKMEZCI, M.; WANG, C. Y. Hot water and curing treatments reduce chilling injury and maintain post-harvest quality of 'Valencia'oranges. International Journal of Food Science and Technology, v. 40, p.91-96, 2005. 
FALLIK, E.; GRIMBERG, S.; ALKALAI, S.; YEKUTIELI, O.; WISEBLUM, A.; REGEV, R.; BERES, H.; BAR - LEV, E. A unique rapid hot water treatment to improve storage quality of sweet pepper. Postharvest Biology and Technology, v.15, p.25-32, 1999.

FALLIK, E.; AHARONI, Y.; COPEL, A.; RODOV, V.; TUVIA - ALKALAI, S.; HOREV, B.; YEKUTIELI, O.; WISEBLUM, A.; REGEV, R. Reduction of postharvest losses of Galia melon by a short hot - water rinse. . Plant Pathology, v.49, p.333-338, 2000.

FERGUSON, I.B.; BEN - YEHOSHUA, S.; MITCHEM, E.J.; McDONALD, R.E.; LURIE, S. Postharvest heat treatments: introduction and workshop summary. Postharvest Biology and Technology, v.21, p.1-6, 2000.

FERNÁNDEZ, M.; RODRÍGUEZ, R.; PICÓ, Y.; MAÑES, J. Liquid chromatographic - mass spectrometric determination of postharvest fungicides in citrus fruits. Journal of Chromatography, v.912, p.301-310, 2001.

FIGUEIREDO, J.O.de. Variedades copa de valor comercial. In: RODRIGUÉZ, O.; VIEGAS, F.; POMPEU JÚNIOR, J.; AMARO, A.A. (Ed.). Citricultura brasileira. 2.ed.Campinas: Fundação Cargill, 1991.v.1, p.228-264.

FNP CONSULTORIA \& COMÉRCIO. Agrianual 2000: anuário estatístico da agricultura brasileira. São Paulo: FNP, 2000. 546p.

FNP CONSULTORIA \& COMÉRCIO. Agrianual 2005: anuário estatístico da agricultura brasileira. São Paulo: FNP, 2005. 520 p. 
FORNEY, C.F. Postharvest response of horticultural products to ozone In HODGES, D.M. Ed Postharvest oxidative stress in horticultural crops. New York: Food Products Press, 2003. cap.2, p.30.

GUERRA, E.; OTERO, O.; MOYA, C.B. Síntesis de los trabajos realizados para el control de las pudriciones postcosecha de los frutos cítyricos en Cuba. Ciência y Técnica en la Agricultura, v.13, n.3/4, p.35-55, 1990.

GONÇALVES, N.B. Efeito da aplicação de cloreto de cálcio associado ao tratamento hidrotérmico sobre a composição química e susceptibilidade ao escurecimento interno do abacaxi 'Smooth cayenne'. Lavras, 1988, 101p. Tese (Doutorado) - Universidade Federal de Lavras.

GONZÁLEZ-AGUILAR, G.A.; GAYOSSO, L.; CRUZ, R.; FORTIZ, J.;BÁEZ, R.; WANG, C.Y. Polyamines ainduced by hot water treatments reduce chilling injury and decay in pepper fruit. Postharvest Biology and Technology, v.18, p.19-25, 2000.

HARA, A.H.; HATA, T.Y.; TENBRINK, V.L.; HU, -S.; KANEKO, R.T. Postharvest heat treatment of red ginger flowers as a posible alternative to chemical inseticidal dip. Postharvest Biology and Technology, v.7, p.137$144,1995$.

HARDENBURG, R.E.; WATADA, A.E.; WANG, C.Y. The commercial storage of fruits, vegetables, and florist, and nursery stocks. Washington: USDA, 1986. 130p. (Agriculture Handbook, 66)

HOLLAND, N. Conservação pós-colheita de pêssegos (cv. 'Biuti'): interação entre cálcio e temperatura. Lavras, 1993. Dissertação (Mestrado) - Escola Superior de Agronomia de Lavras. 
HODGES, D.M. LURIE, S.; KLEIN, J.D. Heat treatment of ripening apples: differential effects on physiology and biochemistry. Physiologia Plantarium, v.78, n.2, p.181-186, 1990.

KADER, A.A. Postharvest handling systems: Subtropical fruits. In: DIVISION OF AGRICULTURE AND NATURAL RESOURCES. Postharvest tecnology of horticultural crops. Califórnia, 1985, p.152 - 156.

KLEIN, J.D.; LURIE, S. Postharvest heat trestment and fruit quality. Postharvest New and Information, v.2, n.1, p.15-19, 1991.

KLUGE, R.A.; SCARPARE FILHO, J.A.; JACOMINO, A.P.; PEIXOTO, C.P. FEALQ: Piracicaba, 2001. Distúrbios fisiológicos em frutos. 58p.

KLUGE, R.A.; NACHTIGAL, J.C.; FACHINELO, J.C.; BILHALVA, A.B. Fisiologia e manejo pós-colheita de frutos de clima temperado. 2.ed. Campinas: livraria e Editora Rural, 2002. 214p.

KOLLER, O.C. Citricultura: laranja, limão e tangerina. Porto Alegre: Editora Rigel, 1994.446p.

LAFUENTE, M.T.; ZACARIAS, L.; MARTINÉZ - TÉLLEZ, M.A.; SANCHEZ BALLESTA, M.T.; DUPILLE, E. Phenylalanine ammonia - lyase as related to ethylene in the development of chilling symptoms during cold storage of citrus fruits. Journal of Agriculture and Food Chemistry, v.49, p.6020 2035, 2001.

LURIE, S. Antioxidants, In HODGES, D.M. (Ed.). Postharvest oxidative stress in horticultural crops. New York: Food Products Press, 2003,cap. 7, p.138-139. 
LURIE, S.; KLEIN, J.D. Heat treatment of ripening apples: differential effects on physiology and biochemistry. Physiologia Plantarium, v.78, n.2, p.181-186, 1990.

LURIE, S.; KLEIN, J.D. Aquisittion of low temperature tolerance in tomatoes by exposure to high temperatures stress. Journal American Society of Horticultural Science, v.116, p.11007 - 1012, 1991.

MARKHART III, A.H. Chilling injury: A review of possible causes. HortScience, v.21, n.6, p.1329-1332, 1986.

MARTÍNEZ-TÉLLEZ, M.A.; LAFUENTE, M.T. Effect of high temperature conditioning on ethylene, phenylalanine ammonia-lyase, peroxidase and polyphenol oxidase activities in flavedo of chilled 'Fortune' mandarin fruit. Journal of Plant Physiology, v.150, p.674-678, 1997.

McCOLLUM, T.G.; D'AQUINO, S.; McDONALD, R.E. Heat treatments inhibt mango chilling injury. HortScience,. v.28, p.197-198, 1993.

McDONALD, R.E.; MILLER, W.R.; McCOLLUM, T.G.; BROWN, G.E. Thiabendazole and Imazalil applied at $53^{\circ} \mathrm{C}$ reduce chilling injury and decay of grapefruit. HortScience, v.26, n.4, p.397-399, 1991.

McGUIRRE, R. G. Reporting of objective color measurements. HortScience, v.27, n.12, p.1254-1255, 1992.

NANOS. G.D.; MITCHELL, F.G. High-temperature conditioning to delay internal breakdown development in peaches and nectarines. HortScience, v.26, n.7, p.882-885, 1991. 
NUNES, E.E. Conservação pós-colheita de pêssegos 'Premier' tratados com cálcio e armazenados em condições ambiente. Lavras, $2003.41 p$. Dissertação (Mestrado) - Universidade Federal de Lavras.

OBAGWU, J.; KORSTEN, L. Integrated control of citrus green and blue mold using bacillus subtilis in conbination with sodium bicarbonate or hot water. Postharvest Biology and Technology, v.28, p.187 - 194, 2002.

PARKING, K.L.; MARAGONI, A.; JACKMAN, R.L.; YADA, R.Y.; STANLEY, W. Chilling injury. A review of possible mechanism. Journal of Food Biochemistry, v.13, p.127-132, 1989.

PAULL, R. E.; CHAN, N.J. Heat treatment and fruit ripening. Postharvest Biology and Technology, v.21, p.21-37, 2000.

PORAT, R.; DAUSS, A.; WEISS, B.; COHEN, L.; DROBY, S. Effects of combing hot water, sodium bicarbonet and biocontol on postharvest decay of citus fruit. Journal of Horticultural Science and Biotechnology, v.77, n.2, $442-445,2002$.

PORAT, R.; POVONCELLO, D.; PERETZ, J.; BEN-YEHOSHUA, S.; LURIE, S. Effect of various heat treatments on the induction of cold tolerance and on the postharvest qualities of 'Star Ruby' grapefruit. Postharvest Biology and Technology, v.18, p.159-165, 2000b.

PORAT, R.; AVINOAM, D.; WEISS, B.; COHEN, L.; FALLIK, E.; DROBY, S. Reduction of postharvest decay in organic citrus fruit by a short hot water brushing treatment. Postharvest Biology and Technology, v.18, p.151157, 2000a. 
RODOV, V.; BEN-YEHOSHUA, S.; ALBAGLI, R.; FANG, D.Q. Reducing chilling injury and decay of stored citrus fruit by hot water dips. Postharvest Biology and Technology, v.5, p.119-127, 1995.

RODOV, V.; AGAR, T.; PERETZ, J.; NAFUSSI, B.; KIM, J.J.; BEN-YEHOSHUA, S. Effect of combined application of heat treatments and plastic packaging on keeping quality of 'Oroblanco' fruit (Citrus grandis L. x C. paradisi Macf.). Postharvest Biology and Technology, v.20, p.287-294, 2000.

SCHIRRA, M.; MULAS, M. Keeping quality of 'Oroblanco' grapefruit-type as affected by hot dip treatments. Advances in Horticultural Science, v.7, p.73-76, 1993.

SCHIRRA, M.; D'HALLEWIN, G. Storage performance of Fortune mandarins follo ing hot water dips. Postharvest Biology and Technology, v.10, p.229238, 1997.

SCHIRRA, M.; AGABBIO, M.; D'HALLEWIN, G.; PALA, M.; RUGGIU, R. Responses of Tarocco oranges to picking date, postharvest hot water dip, and chilling storage temperature. Journal of Agriculture and Food Chemistry, v,45, p.3216-3220, 1997a.

SCHIRRA, M.; CABRAS, P.; ANGIONI, A.; D'HALLEWIN, G.; RUGGIU, R.; MINELLI, E. Effect of heated solutions on decay control and residues of Imazalil in lemons. Journal of Agriculture and Food Chemistry, v.45, p.4127-4130, 1997b. 
SCHIRRA,M.; 'HALLEWIN, G.; CABRAS, P.; ANGIONI, A.; BEN - YEHOSHUA, S.; LURIE, L. Chilling injury and residue uptake in cold - stored 'Star Ruby' grapefruit following thiabendazole and imazalil dip treatments at 20 and $50^{\circ} \mathrm{C}$. Postharvest Biology and Technology, v.20, p.91-98, 2000.

SIEGEL, S.M.; SIEGEL, B.Z. Peroxidase activity and stress: a complex relationship. In: GREPPIN, H.; PENEL, C.; GASPAR, T.H. (Ed.). Molecular and physiological aspects of plant peroxidases. Geneva University, 1986. p.427-432.

THÉ, P.M.P. Efeitos da associação de tratamento hidrotérmico, cloreto de cálcio e atmosfera sobre o escurecimento interno e qualidade do abacaxi 'Smooth cayenne'. Lavras, 2001. 128p. Tese (Doutorado) - Universidade Federal de Lavras.

TING, S.V.; ROUSSEF, R.L. Citrus fruits and their products: analysis y technology. New York: Marcel Deker, 1986. 293p.

VALDERAMA, P.; MARANGONI, F.; CLEMENTE, E. Efeito do tratamento térmico sobre a atividade da peroxidase (POD) e polifenoloxidase (PPO) em maçã (Mallus comunis). Revista Ciência e Tecnologia de Alimentos, v. 21, n.3, p. 321-325, 2001.

WANG , C. Y. Physiological and biochemical responses of plants to chilling stress. HortScience, v.17, n.2, p.173 - 186, 1982.

WANG , C. Y. Approaches to reduce chilling injury of fruit end vegetables. Horticultural Reviews, v.15, p.63 - 95, 1993. 
WANG , C. Y. Combined treatments of heat shock and low temperature conditioning reduces chilling injury in zuchini squash Postharvest Biology and Technology, v.4, p.65-73, 1994a.

WANG, C.Y. Chilling injury of tropical horticultural commodities HortScience, v.29, n.9, p. 986-988, 1994b

WILLS, R.H.H.; McGLASSON, B.; GRAHAM, D.; JOYCE, D. Introducción a la fisiologia y manipulación poscosecha de frutas, horatizas y plantas ornamentales. 2.ed. Trad. De j.b. Gonzalez-Zaragoza Acribia, 1998. 240p.

WILD, B.L.; HOOD, C.W. Hot dip treatments reduce chilling injury in long-term storage of 'Valencia' oranges. HortScience, v.24, n.1, p.109-110, 1989.

WOOLF, A.B.; LAY-YEE, M. Pretreatments at $38^{\circ} \mathrm{C}$ of "Hass" avocado confer thermotolerance to $50^{\circ} \mathrm{C}$ hot water treatments. HortScience, v.20, n.1, p.4145, 1985.

ZHOU, T.; SHYING, X.; SUN, D.; WANG, C.Y. Effects of heat treatment on postharvest quality of peaches. Journal of Food Engineering, n.54, p.17 23, 2002. 